\title{
Los derechos y deberes en el nuevo Estatuto de Autonomía para Andalucía*
}

\author{
Ángel Rodríguez \\ Catedrático de Derecho Constitucional \\ Universidad de Málaga
}

\begin{abstract}
SUMARIO: 0. INTRODUCCIÓN. 1. DISPOSICIONES GENERALES.- 1.1. Sujetos de los derechos.- 1.2. Cláusulas interpretativas.- 1.3. Cláusula competencial.- 2. EL CATÁLOGO DE DERECHOS.- 2.1. Las concreciones estatutarias del derecho constitucional a la igualdad.- 2.2. Normas que añaden un contenido estatutario a derechos constitucionales.- 2.3. Derechos estatutarios que dotan de contenido a los principios rectores constitucionales.- 2.4. «Nuevos» derechos.- 3. DEBERES.- 4. PRINCIPIOS RECTORES ESTATUTARIOS.- 5. LAS GARANTÍAS.- 5.1. Desarrollo de los derechos.- 5.2. Protección jurisdiccional de los derechos.- 5.3. Efectividad de los principios rectores.- 5.4. Defensor del Pueblo y otras instituciones.- 6. NOTA BIBLIOGRÁFICA.-
\end{abstract}

\section{INTRODUCCIÓN}

En junio de 2001, el primer Estatuto de Autonomía de la Comunidad Autónoma de Andalucía (CAA), el denominado Estatuto de Carmona (citado en adelante como EAA 1981), llevaba veinte años en vigor, con un texto que había permanecido durante todo ese tiempo inalterado ${ }^{1}$. Fue probablemente en el debate parlamentario sobre el estado de la Comunidad de ese año cuando

\footnotetext{
* Este trabajo forma parte del proyecto de investigación "Derechos, deberes y principios rectores en el nuevo estatuto de autonomía para Andalucía. Perspectiva comparada" financiado por la Fundación Centro de Estudios Andaluces para el año 2007, con la referencia DCHD 3.07/088, y cuyo investigador principal es Gregorio Cámara Villar, catedrático de Derecho Constitucional de la Universidad de Granada.

${ }^{1}$ Aprobado mediante Ley Orgánica 6/1981, de 30 de diciembre.
} 
se introdujo en la agenda política de la CAA la cuestión de la reforma estatutaria $^{2}$. El proceso entonces iniciado culminó seis años más tarde, a principios de 2007, con la entrada en vigor de un nuevo Estatuto de Autonomía para Andalucía (citado en adelante como EAA o, cuando hubiese que hacer esa precisión, como EAA 2007) $)^{3}$.

Como todos los Estatutos aprobados en aquella época, el EAA 1981 no contenía una Declaración de Derechos. La "parte dogmática" del Estatuto se reducía exclusivamente a una referencia genérica a los derechos fundamentales establecidos en la Constitución ${ }^{4}$. No se aprecia en los primeros debates parlamentarios sobre la reforma estatutaria que ello se percibiera como una deficiencia que hubiera que remediar. Más bien, la justificación de la reforma se buscaba en la consolidación del autogobierno mediante el incremento del techo competencial ${ }^{5}$. No obstante, cuando, de nuevo con ocasión de un debate sobre el estado de la Comunidad, esta vez en el año 2003, dos años después de aludir por primera vez a la reforma estatutaria en el Parlamento, el Presidente de la Junta anunció el envío a la Cámara de un documento de bases sobre la misma, incorporó a su discurso la idea de una "modernización" de la CA

\footnotetext{
${ }^{2}$ Ligada por el Presidente de la Comunidad, Manuel Chaves (PSOE), pero sólo "si fuera necesario", a la idea general de una "segunda modernización" (tras la que supuso la instauración de Estado de las Autonomías) para la región. Su intervención en el Pleno del Parlamento “(...) como ya tenemos consolidadas las instituciones andaluzas, debemos abrir un debate político y social sobre el texto estatutario, evitando la polémica partidista, y proceder, entre todos, con inteligencia, con pragmatismo e impulsar un nuevo horizonte de autogobierno que facilite lo que vengo en denominar "la segunda modernización de Andalucía", y debemos hacerlo en base a sugerencias, propuestas e iniciativas, sin excluir ninguna alternativa, incluida la posibilidad de reformar el Estatuto de Autonomía para Andalucía, si ello fuera necesario." (Diario de Sesiones del Parlamento de Andalucía, Pleno, 28 de junio de 2001, p. 2948).
}

${ }^{3}$ Aprobado mediante Ley Orgánica 2/2007, de 19 de marzo, de Reforma del Estatuto de Autonomía para Andalucía.

${ }^{4}$ Según el art. 11 EAA 1981, "Los derechos, libertades y deberes fundamentales de los andaluces son los establecidos en la Constitución (...)".

${ }^{5}$ Así, por ejemplo, en la intervención parlamentaria del portavoz José Antonio CABallos MoJEDA (PSOE), en el mismo debate sobre el estado de la Comunidad de 2001 en el que se habló por primera vez de reformas estatutarias, que se refería a las mismas como "una reforma del Estatuto de Autonomía para Andalucía, que nos dé más poder político, que nos dé más competencias, que nos dé más potencialidades (...)" (Diario de Sesiones del Parlamento de Andalucía, Pleno, 28 de junio de 2001, p. 3008). 
también en materia de derechos ${ }^{6}$. Este documento - las Bases para la Reforma del Estatuto de Autonomía para Andalucía - sí contenía ya un apartado específico - la base segunda - con una alusión directa a la necesidad de que el proceso de reforma tuviera en cuenta de alguna manera nuevos derechos en el ámbito de la Comunidad Autónoma ${ }^{7}$.

A partir de entonces, y conforme avanzaba el debate parlamentario y social sobre la reforma, a lo largo de los años 2004, 2005 y 2006, la incorporación de una tabla de derechos al nuevo Estatuto se fue progresivamente convirtiendo, según sus impulsores, en una de sus señas de identidad. Ya en la proposición de reforma presentada al Parlamento conjuntamente por los grupos

6 “Como Presidente de la Junta de Andalucía, abrí el debate sobre el papel del Estatuto (...) incluso su reforma, si se considerara necesaria (...) es mi intención presentar ante esta Cámara, en el próximo período de sesiones, un documento de propuestas para ser sometido a debate por las distintas fuerzas políticas" (intervención del Presidente CHAVES, en Diario de Sesiones del Parlamento de Andalucía, Pleno, 25 de junio de 2003, p. 7736). En el debate, que seguía girando sobre la llamada "segunda modernización", se aludió a la necesidad de incorporar al ordenamiento andaluz nuevos derechos de los ciudadanos, con al menos cinco menciones en el discurso del Presidente de la Junta, entre ellas "segunda modernización es establecer nuevos derechos" (ídem, p, 7737), pero sin una formulación clara de si los mismos debían llevarse o no a la, aún eventual, "si fuera necesaria" - reforma estatutaria. Sólo en algunas intervenciones parlamentarias aisladas - como la del diputado Antonio ROMERO RUIZ (IU) - se afirmó expresamente la necesidad de "ir a una reforma del Estatuto que integre nuevos derechos de ciudadanía, que amplíe el autogobierno y que alumbre un Estado federal y solidario sin privilegios" (idem, p. 7773).

7 Bases para la Reforma del Estatuto de Autonomía para Andalucía, de 16 de diciembre de 2003. Aunque la base segunda no contenía un mandato directo de inclusión de una tabla de derechos en el Estatuto, y apuntaba más bien a una "Carta de Derechos Sociales de los Andaluces" que tendría carácter extraestatutario, sí puede considerarse el germen de la idea de incorporar una parte dogmática en el nuevo Estatuto. En ella se hace ya referencia a muchos de los temas que serían más tarde objeto de regulación mediante derechos estatutarios, como la igualdad de género, las nuevas causas de discriminación, la voluntad vital anticipada o el acceso a las tecnologías de la información. El texto de las Bases se encuentra en línea en la web del Parlamento de Andalucía en http://www.parlamentodeandalucia.es/opencms/export/portal-web-parlamento/contenidos/ pdf/SecretariaGeneralAdjunta/basereforma/BasesReformaEAA.pdf (visitado el 22 de mayo de 2007). Ya con ocasión del debate de las bases, la oposición mayoritaria en el Parlamento (PP) incluyó su desacuerdo sobre la necesidad de establecer nuevos derechos entre sus argumentos para oponerse a una reforma estatutaria, aludiendo a que la instauración efectiva de los mismos se encontraba ya en los diferentes instrumentos legislativos que lo regulaban: "la Carta de los derechos sociales a que se refiere la segunda de sus bases ya está vigente, señor Chaves...” [portavoz Teófila MARTÍNEZ (PP), Diario de Sesiones del Parlamento de Andalucía, Pleno, 30 de diciembre de 2003 p. 9112]. 
socialista y de izquierda unida se incluía un nuevo Título, el primero, dedicado específicamente a esta cuestión, presentado en el Parlamento como "modelo y pauta a seguir en otras Comunidades (...) que consolida derechos y políticas públicas que representan auténticas conquistas sociales en nuestra tierra" ${ }^{8}$. Y cuando, finalmente, la propuesta de reforma fue aprobada por el Parlamento y enviada a las Cortes Generales, el portavoz del grupo que apoyaba al gobierno -el socialista- pudo afirmar ante el Pleno, refiriéndose al título sobre derechos y deberes, que "nos podemos sentir satisfechos y orgullosos de esta propuesta de Estatuto, pero especialmente de este Título nuevo" ${ }^{\text {. }}$

El resultado final de todo ello, tras las correspondientes enmiendas aprobadas por las Cortes Generales, ha sido la inclusión en el Estatuto de 2007 de un extenso Título I, de veintinueve artículos (del 12 al 41), dedicado a los "derechos sociales, deberes y políticas públicas" ${ }^{10}$. El título se divide en dos capítulos, de los cuales sólo el segundo y el tercero tienen carácter sustantivo. El capítulo segundo contiene los "derechos y deberes" (arts. 15-36) y el capítulo III los "principios rectores de las políticas públicas" (art. 38). Los capítulos primero (arts. 12-24) y cuarto (arts. 38-41) se dedican, respectivamente, a cuestiones generales (establecer los sujetos de los derechos, una cláusula competencial y otras de carácter interpretativo) y a las garantías (de desarrollo de los derechos, su protección jurisdiccional, la efectividad de los principios y el Defensor del Pueblo).

Las semejanzas entre la estructura del Título I CE y el Título I EAA son, pues, notables (y las diferencias más acusadas, la lógica inexistencia de un capítulo sobre suspensión de derechos y la no subdivisión del capítulo II en sec-

\footnotetext{
${ }^{8}$ Proposición de reforma del Estatuto de Autonomía para Andalucía, Presentada por los Grupos Parlamentarios Socialista e Izquierda Unida Los Verdes-Convocatoria por Andalucía, Boletín Oficial del Parlamento de Andalucía 374, de 9 de febrero de 2006, pp. 21054 y ss. El texto entrecomillado pertenece al portavoz Manuel GRACIA NAVARRO (PSOE) en su intervención ante la Cámara en defensa de la proposición de reforma, Diario de Sesiones del Parlamento de Andalucía, Pleno, 16 de febrero de 2006, p.4618.

${ }^{9}$ Diputado José Antonio CABALLOS MOJEDA, actuando como portavoz (PSOE), Diario de Sesiones del Parlamento de Andalucía, Pleno, 2 de mayo de 2006 p.5326.

${ }^{10}$ Esta es la rúbrica del Título I, consecuencia, sin duda, de su primigenia concepción como una tabla de derechos "sociales". En realidad, como veremos, en el Título I hay también derechos que difícilmente entrarían en el grupo de lo que comúnmente consideramos como "derechos sociales".
} 
ciones $)^{11}$. Hasta la prohibición de la discriminación, también en el art. 14 EAA, se ha sacado del capítulo II (en la CE, el art. 14 se encuentra fuera de sus secciones), con la evidente intención de proyectarla - así se recoge en su tenor literal - sobre todos los derechos.

La mayoría de los derechos y principios que se recogen en los capítulos II y III del Título I del Estatuto no son nuevos. Muchos de ellos están ya en la Constitución, como el propio Estatuto reconoce en ocasiones al referirse a los mismos $^{12}$. Y otros tantos se encontraban recogidos en la legislación sectorial autonómica, por ejemplo, sobre voluntades vitales anticipadas, menores, parejas de hecho o usuarios del sistema andaluz de salud ${ }^{13}$. Lo más relevante de su consagración estatutaria es pues, con respecto a los primeros, la adición de un contenido estatutario al propiamente constitucional y, con respecto a los segundos, su elevación de rango e instalación en una situación de indisponibilidad para el legislador autonómico.

En las líneas que siguen se dará cuenta, al poco tiempo de su entrada en vigor, de la tabla de derechos recogida en el Estatuto de Andalucía de 2007 y se revisarán de manera genérica algunos de los problemas a los que apuntan las normas que los consagran, haciendo, cuando sea necesario, una breve referencia a cuestiones de mayor alcance sobre la naturaleza de estos nuevos derechos estatutarios, una categoría que está aún por construir en nuestro ordenamiento doctrinal y jurisprudencialmente. La intención del trabajo se reduce, pues, a dar una primera visión panorámica (y, por lo tanto, necesariamente sucinta en cada uno de sus aspectos concretos) del Título I EAA.

\footnotetext{
11 Efectivamente, el capítulo II del Título I EAA, a diferencia del de la CE, no se subdivide a su vez en secciones. Como se ve más adelante, el Estatuto apunta, aunque no establece, un "amparo autonómico" para los derechos estatutarios, pero a diferencia del amparo ante el Tribunal Constitucional, éste sería en todo caso el mismo para todos los derechos estatutarios.

12 Expresamente se hace, a lo largo del título I EAA, en cuatro ocasiones: las que se refieren al "derecho constitucional de todos a una educación permanente y de carácter compensatorio" (art. 21.1 EAA), al "derecho constitucional previsto en el artículo 43 de la Constitución Española a la protección de la salud" (art. 22 EAA), al "derecho constitucional a una vivienda digna" (art. 25 EAA) y al "derecho constitucional al trabajo" (art. 26.1 EAA). Por su parte, el art. 36 EAA establece una serie de deberes estatutarios, "sin perjuicio de los deberes constitucionalmente establecidos".

13 Respectivamente, en la Ley 5/2003, de 9 de octubre, de Declaración de Voluntad Vital Anticipada; la Ley 1/1998, de 20 de abril, de los Derechos y la Atención al Menor; la Ley 5/2002, de 16 de diciembre, de Parejas de Hecho; o la Ley 2/1998, de 15 de junio, de Salud de Andalucía.
} 
Seguiremos para ello, en cierta medida, la propia sistematización presente en el Estatuto: el primer epígrafe se dedicará a las disposiciones generales, el segundo al catálogo de derechos sustantivos establecidos, el tercero a los deberes, el cuarto a los principios rectores y el quinto a las garantías. Con respecto a los derechos estatutarios estudiados en el segundo epígrafe - el más extenso - el texto se distanciará del orden asistemático por el que éstos se establecen en el Estatuto y se procederá a una agrupación de los mismos en función de su relación con los derechos constitucionales, distinguiendo así entre las concreciones estatutarias del derecho constitucional a la igualdad, los derechos que añaden un contenido estatutario a derechos fundamentales, los que dotan de contenido a principios rectores de la política social y económica y, finalmente, los derechos que están en el Estatuto pero no en la Constitución.

\section{DISPOSICIONES GENERALES}

\subsection{Sujetos de los derechos}

Por lo que hace al sujeto pasivo de los derechos estatutarios, el art. 38 EAA tercia en la vieja polémica sobre la efectividad de los derechos fundamentales entre particulares para proclamar que tanto la prohibición de discriminación como el resto de los derechos reconocidos en el capítulo II "vinculan a todos los poderes públicos andaluces y, dependiendo de la naturaleza de cada derecho, a los particulares (...)"14.

Puede, pues, afirmarse que los sujetos pasivos de los derechos estatutarios pueden ser tanto públicos como privados. En cuanto a los sujetos pasivos públicos, la definición amplia que ofrece esta disposición - "todos los poderes públicos andaluces" - permite incluir entre los mismos, junto con la administración autonómica, a las administraciones locales de la CAA. En cuanto a los sujetos pasivos privados, el criterio usado por el Estatuto - "dependiendo de la naturaleza de cada derecho" - exigirá indagar en cada caso qué derechos pueden ser ejercitables inter privatos y cuales no. Con respecto a los sujetos activos, según el art. 12 EAA,

\footnotetext{
${ }^{14}$ La propuesta aprobada por el Parlamento de Andalucía afirmaba a este respecto que los derechos, dependiendo de su naturaleza, podrían vincular no sólo a los poderes públicos andaluces sino también "a los ciudadanos andaluces", reduciendo así el ámbito de la efectividad entre privados a una peculiar drittwirkung que estaría condicionada por la condición política del sujeto pasivo. Este despropósito fue enmendado por las Cortes Generales.
} 
"Los destinatarios de las políticas públicas y los titulares de los derechos y deberes contenidos en este Título I son todas las personas con vecindad administrativa en Andalucía, sin perjuicio de lo establecido para el derecho de participación en los asuntos públicos en el Artículo 30 y de acuerdo con las leyes reguladoras de los Derechos Fundamentales y Libertades Públicas"

$\mathrm{Al}$ menos tres cuestiones plantea esta disposición, todas ellas en relación con los extranjeros como sujetos activos de los derechos estatutarios: el concepto de "vecindad administrativa" que se toma como criterio para atribuir la titularidad de los mismos y las matizaciones que sobre ésta introducen los dos incisos siguientes.

La elección del criterio de "vecindad administrativa" apunta, sin duda, a una evidente vocación por hacer universal la titularidad de los derechos estatutarios. Es el mismo concepto que se usa en el art. 5 EAA como criterio para gozar de la "condición política de andaluz", pero combinándolo con la exigencia de ser "ciudadanos españoles". Al no estar presente ahora este último requisito, queda pues claro que son también titulares de los derechos estatutarios aquellos que, careciendo de la condición política de andaluz por no ser españoles, tengan sin embargo en Andalucía su vecindad administrativa, debiendo entenderse por tal la que se adquiere al inscribirse en el Padrón de habitantes de un municipio de la CAA.

La inscripción padronal, como se sabe, tiene como objetivo que se encuentren registradas todas las personas que de hecho viven en el municipio. Por esta razón, la misma no es, en el caso de los extranjeros, prueba de residencia regular en nuestro país y, precisamente por ello, es posible que puedan inscribirse en el Padrón extranjeros que carecen de tarjeta de residencia y se encuentran en España en situación irregular. El Estatuto, al establecer como criterio para la titularidad de los derechos este concepto más amplio de "vecindad administrativa" y no el más restringido de "residencia", contempla pues una legitimación activa muy generosa para el ejercicio de los derechos estatutarios: todos los extranjeros que vivan en Andalucía, incluso si no son residentes regulares, pueden ser titulares de los derechos estatutarios con la única condición de estar inscritos en el padrón de algún municipio andaluz.

Si la persona que adquiere de este modo la vecindad administrativa tiene, además, la nacionalidad española, gozará de la "condición política de andaluz”, relevante para el ejercicio del derecho de participación en los asuntos públicos. Efectivamente, ésta es la primera matización al principio general sobre la titularidad de los derechos estatutarios que contempla el art. 12 EAA. Según 
la misma, la vinculación exclusiva de la titularidad a la vecindad administrativa debe entenderse "sin perjuicio de lo establecido para el derecho de participación en los asuntos públicos en el artículo 30”. A su vez, esta disposición atribuye la titularidad activa de este derecho, "conforme al artículo 5", a "los andaluces y andaluzas".

La excepción que supone que los extranjeros no puedan ser titulares del derecho de participación política trae causa de la que por su parte establece el art. $13 \mathrm{CE}$, existiendo sin embargo una diferencia digna de ser resaltada entre la Constitución y el Estatuto a este respecto: no hay en el Estatuto una llamada al legislador (o a los tratados), tal como existe en la Constitución, para establecer "los términos" en los que los extranjeros podrán ser titulares de derechos. Con independencia de la penumbra jurisprudencial que se cierne, al menos en tanto no recaiga sentencia sobre el recurso de inconstitucionalidad contra la LODLEIS ${ }^{15}$, sobre la correcta interpretación de esta remisión en la CE (hasta el punto de que puede afirmarse que "al día de hoy no existe una construcción dogmática clara respecto del régimen jurídico constitucional de los extranjeros en nuestro país"), la ausencia de la misma en el Estatuto apunta a que el legislador autonómico no podría, a diferencia del estatal, condicionar para los extranjeros el ejercicio de los derechos estatutarios al cumplimiento de determinados requisitos más allá de los exigibles a los españoles (y que se reducen, como se ha visto, a la vecindad administrativa), con la única excepción del de la participación en los asuntos públicos de la Comunidad. Por otra parte, y del mismo modo que el art. 13.2 CE abre la puerta a que los extranjeros ejerzan el derecho de participación en las elecciones municipales, el art. 30 EAA ordena a la Junta que establezca mecanismos para extender todos los derechos de participación que contempla (el elenco se ve más adelante en su correspondiente epígrafe) a los extranjeros "residentes" en Andalucía, siempre que lo permita la Constitución.

La segunda matización del art. 12 EAA con respecto a la titularidad activa de los derechos estatutarios es que la misma deberá entenderse "de acuerdo con las leyes reguladoras de los Derechos Fundamentales y Libertades Públicas". La elección por el estatuyente de este "dictum" constitucional, de interpretación pacífica, supone remitir a las normas estatales que desarrollen los derechos y libertades sometidos constitucionalmente a reserva de Ley Orgánica. Implica, en consecuencia, deferir al Estado la concreción de quienes pue-

\footnotetext{
${ }^{15}$ Ley Orgánica de los Derechos y Libertades de los Extranjeros y de su Integración Social, en la versión reformada por la Ley 8/2000.
} 
den ser sujetos activos de estos derechos, incluso en lo que hace a su contenido específicamente estatutario.

De manera que aunque el Estatuto, como se ve más adelante, establezca un contenido propio en materia de algunos derechos fundamentales sometidos a reserva de Ley Orgánica, el propio art. 12 EAA reconoce que la cuestión de su titularidad no queda extramuros de la capacidad normadora del Estado. Ahora bien, lo anterior no puede impedir que, en el caso de derechos estatutarios no sometidos a reserva de Ley Orgánica, la norma estatutaria lleve a cabo una atribución más generosa de la titularidad de los mismos que la que haya decidido el legislador estatal ${ }^{16}$.

\subsection{Cláusulas interpretativas}

Esta línea de argumentación, que conduce a afirmar que el Estatuto puede, en materia no reservada a la Ley Orgánica, extender la titularidad de los derechos estatutarios más allá de lo que contemple la legislación del Estado, es acorde con lo que, a un nivel más general, disponen las cláusulas interpretativas que, a modo de canon hermenéutico en materia de derechos, contiene el propio Estatuto. Hay, al menos, tres de ellas: la relativa al "mínimo estándar", la que obliga a interpretar las disposiciones estatutarias según el principio favor libertatis y la específica sobre el interés del menor.

La consideración de un "suelo" común o estándar mínimo de derechos sobre el cual pueda luego disponerse un estándar de protección más amplio es bien conocida, en general, como unos de los principios básicos del denominado "constitucionalismo multinivel" y se ha venido aplicando, en particular, para disciplinar las relaciones en materia de derechos entre los Estados federales y las entidades subestatales. Esta cláusula ha sido incorporada en el Estatuto en dos momentos diferentes: así, en el segundo inciso del art. 13 EAA, que dispone que ninguno de los derechos o principios del Título I EAA puede ser "interpretado, desarrollado o aplicado de modo que se limiten o reduzcan derechos o principios reconocidos por la Constitución o por los tratados y convenios internacionales ratificados por España”. Pero también en el

\footnotetext{
${ }^{16}$ Es el caso de derechos estatutarios para cuya titularidad basta la vecindad administrativa, pero que la LODLEIS supedita a la obtención de un certificado de residencia en España (por ejemplo: el acceso a servicios y prestaciones sociales no básicas (art. 14.2 LODLEIS), a las ayudas públicas en materia de de vivienda (art. 13 LODLEIS) o a la asistencia jurídica gratuita (art. 22 LODLEIS).
} 
art. 9.1 EAA, una disposición del Título Preliminar, según la cual "todas las personas en Andalucía gozan como mínimo de los derechos reconocidos en la Declaración Universal de Derechos Humanos y demás instrumentos europeos e internacionales de protección de los mismos ratificados por España", nombrándose algunos de ellos a renglón seguido "en particular"17.

A pesar de que su recepción estatutaria presenta algunas deficiencias (no sólo su redundancia: el art. 9.1 comete el exceso de enumerar algunos tratados en concreto y el defecto de omitir la Constitución) ${ }^{18}$, la cláusula estatutaria de mínimo estándar arroja suficiente luz sobre la concepción que de los derechos del Título I EAA tiene el estatuyente: pueden proyectarse sobre derechos ya establecidos por la Constitución o por normas internacionales, pero sólo para aportar un plus de protección a los mismos. En líneas generales, pues, puede augurarse que la aplicación futura de estas disposiciones está llamada a rodearse de los mismos problemas que el principio de "mínimo estándar" ha originado en otros contextos.

Precisamente uno de estos problemas, el que se da cuando nos encontramos ante un conflicto de derechos (el mayor estándar de protección del primero implica aminorar el del segundo), es el que reduce drásticamente la utilidad del segundo principio sobre interpretación de derechos estatutarios, el de favor libertatis. Lo establece el art. 38 EAA, que ordena que los derechos reconocidos del capítulo II del Título I sean "interpretados en el sentido más favorable a su plena efectividad". Con independencia de que la cláusula debería haberse hecho extensiva también a los principios rectores del capítulo III - de hecho, es de mayor utilidad, dada la naturaleza de los principios, en esa sede -, lo cierto es que las posibilidades de su aplicación efectiva son pocas: fruto de la tendencia, que el propio Estatuto consolida, de reconocer como fundamentales un catálogo cada vez más amplio de derechos, será frecuente que el límite que permite restringir un derecho estatutario sea otro bien jurídico que a su

\footnotetext{
${ }^{17} \mathrm{El}$ art. 9.1 EAA nombra expresamente los Pactos Internacionales de Derechos Civiles y Políticos y de Derechos Económicos, Sociales y Culturales, el Convenio Europeo para la Protección de los Derechos Humanos y de las Libertades Fundamentales y la Carta Social Europea.

${ }^{18}$ Pero es a su vez más correcta que la correspondiente cláusula del art. 10.2 CE, que establece como se sabe un mandato de interpretación de las normas internas sobre derechos fundamentales "de conformidad" con la DUDH y los tratados internacionales. Aunque es pacífico que este "de conformidad con" es también una cláusula de mínimos, una afirmación más precisa de la CE habría probablemente evitado algunas interpretaciones jurisprudenciales en un sentido diferente.
} 
vez se ha reconocido también como derecho estatutario, con lo que es imposible una interpretación de los mismos tendente a la plena efectividad de ambos.

En una ocasión, sin embargo, el Estatuto ha optado expresamente por uno de los bienes potencialmente en conflicto: se trata del mandato que establece que "el beneficio de las personas menores de edad primará en la interpretación y aplicación de la legislación aplicable a éstos” (art. 18.2 EAA). Este canon es también aplicable a los propios derechos estatutarios, de modo que, por mandato del estatuyente, en los casos en los que una de las partes concernidas sea un menor de edad el principio favor libertatis cede para una mejor protección del beneficio de éste, incluso cuando ello conlleve una restricción mayor de otros derechos estatutarios también en presencia.

\subsection{Cláusula competencial}

La inclusión en los Estatutos de Autonomía de una parte dogmática ha puesto de nuevo de relieve lo que podríamos calificar como el "problema competencial”. Este implica no sólo responder a la pregunta acerca de si las CCAA pueden incorporar a sus Estatutos nuevos derechos subjetivos de los ciudadanos, algunos incluso ya contemplados constitucionalmente, sino abordar también la cuestión de si son necesarios, y en qué medida, títulos competenciales propios para hacerlo así. Dicho en otras palabras, dilucidar si las CCAA sólo podrán vincularse mediante su propio ordenamiento al respeto de aquellos derechos sobre los que pueda proyectarse alguna de sus competencias.

En el caso del Estatuto de Andalucía, la cuestión se saldó con el añadido, durante el trámite de debate y enmienda en las Cortes Generales, del que finalmente ha resultado ser primer párrafo del art. 13 EAA (a pesar de que habría merecido, como inmediatamente se verá, una disposición propia). Se trata de la norma que impide considerar los derechos y principios del Título I EAA como títulos competenciales. En su formulación literal, se establece que los mismos "no supondrán una alteración del régimen de distribución de competencias, ni la creación de títulos competenciales nuevos o la modificación de los ya existentes".

Como se sabe, la primera ocasión en la que se planteó el problema competencial en relación con la protección de derechos fue, mutatis mutandis, la aprobación de la Bill of Rights de la Constitución de los Estados Unidos. Y la más reciente, en relación con la aprobación de la Carta de Derechos Fundamentales de la Unión Europea (CDFUE). De hecho, el artículo de la CDFUE que aclara que la misma no supone ningún título competencial nuevo para la 
Unión es, claramente, la fuente de inspiración de este inciso del art. 13 EAA $^{19}$. Su transposición entre nosotros abre sin embargo, como no puede ser de otra manera, interrogantes que sólo podrán ser resueltos en el contexto que impone el Estado autonómico, muy distinto, a este respecto, del de la UE.

Así, en primer lugar, la no idoneidad de la norma estatutaria que establece un derecho o un principio rector para contener también un específico título competencial casa mal con el carácter "social" que el estatuyente ha querido dar al Título I EAA. La idea de que la norma establecedora de derechos supone ante todo un límite a la actuación del poder es evidentemente tributaria de una concepción liberal de los derechos fundamentales, en la que no es necesario, ni siquiera conveniente, que la misma habilite a los poderes públicos para la acción. Pero deviene insuficiente para los derechos prestacionales propios del Estado Social, donde la labor de desarrollo del legislador es la que da realmente vida al derecho. No en vano el art. 38 EAA, cuando ordena al legislador autonómico el desarrollo de los derechos estatuarios le exige que determine, en su caso, "las prestaciones y servicios vinculados" a su ejercicio.

Fue precisamente el temor a que la CDFUE habilitara al legislador comunitario para implementar una prácticas de desarrollo de los derechos allí establecidos lo que motivó la cláusula de limitación competencial en la que se inspira directamente el art. 13 EAA. De este modo, los Estados miembros más críticos con la europeización de los derechos fundamentales, sobre todo de los de carácter social, consiguieron que en buena medida los mismos se siguieran considerando competencia estatal. En nuestro Estado autonómico, sin embargo, los principales actores sociales son ya las Comunidades Autónomas. Privar de carácter competencial a las disposiciones estatutarias que establecen derechos de esta naturaleza obliga a subordinar los mandatos que las mismas puedan contener con respecto a los poderes públicos autonómicos a lo dispuesto en el título competencial correspondiente, un título competencial que habrá que buscar en una disposición distinta de la que establece el derecho estatutario.

${ }^{19}$ Art. 51.2 CDFUE, según el cual "La presente Carta no crea ninguna competencia ni ninguna misión nuevas para la Comunidad ni para la Unión y no modifica las competencias y misiones definidas por los Tratados". 
No quiere decirse con ello que las disposiciones estatutarias que establecen derechos no vinculen de por sí, incluso en ausencia de desarrollo, a los poderes públicos (ver más adelante). Pero la exigencia de incluir en el análisis de cada uno de los derechos del Título I EAA lo que disponga el título competencial correspondiente condiciona lógicamente el mandato de desarrollo de los mismos, que sólo será posible en los casos y con los límites que permita la norma estatutaria habilitadora de la competencia. Cuando, como se ve más adelante, el título competencial no permita este desarrollo (bien por no incluir medidas legislativas, bien porque sencillamente no exista), nos encontraremos ante un derecho autonómico de contenido exclusivamente estatutario, de imposible concreción por el legislador, lo que a veces (siempre, si se trata de un derecho prestacional) condicionará de manera inevitable su ejercicio.

Que el desarrollo de los derechos sólo sea posible cuando exista una competencia autonómica para ello exige también analizar la incidencia que en el régimen autonómico de los mismos tienen las competencias del Estado, en la medida en que en nuestro sistema de organización territorial éstas pueden condicionar el despliegue de aquéllas. Y ello, tanto en relación con los títulos competenciales específicos que sean de aplicación en cada caso, como con el título competencial "horizontal" en materia de derechos fundamentales que supone el art. 1491.1.1 ${ }^{\circ} \mathrm{CE}$, al habilitar al Estado para regular "las condiciones básicas que garanticen la igualdad de todos los españoles en el ejercicio de los derechos y en el cumplimiento de los deberes constitucionales".

Todo lo anterior confirma que la inclusión de una tabla de derechos no implica que el cometido esencial del Estatuto deje de ser la atribución de competencias a la Comunidad Autónoma: también en el caso de los derechos estatutarios la titularidad de la competencia seguirá siendo muy relevante. Aunque con toda seguridad la aparición de las partes dogmáticas en los Estatutos de Autonomía enriquecerá la idea que hasta ahora hemos tenido de los mismos como "norma institucional básica de la Comunidad Autónoma" (art. 147.1 CE), la paulatina construcción doctrinal y jurisprudencial de los derechos estatutarios seguirá muy probablemente haciéndose en clave competencial.

\section{EL CATÁLOGO DE DERECHOS}

Como se ha dicho, la mayoría de los derechos contemplados en el Estatuto ya lo están por la Constitución, bajo la forma de derechos fundamentales o principios rectores. En los epígrafes que siguen, estos derechos se clasificarán del siguiente modo: en primer lugar, las concreciones estatutarias del de- 
recho constitucional a la igualdad; en segundo lugar, los derechos estatutarios que añaden un contenido propio a determinados derechos constitucionales; en tercer lugar, derechos estatutarios que dotan de contenido a los principios rectores constitucionales. Y, en cuarto lugar, los "nuevos" derechos que aparecen en el Estatuto, pero que no están contemplados por la Constitución.

\subsection{Las concreciones estatutarias del derecho constitucional a la igualdad}

Como se sabe, el derecho constitucional a la igualdad y la interdicción de discriminación del art. $14 \mathrm{CE}$ no se encuentran sometidos a una reserva de Ley Orgánica en su legislación de desarrollo, que sólo deberá tener ese carácter cuando así venga requerido por el derecho sustantivo en cuyo seno se regulen las condiciones de igualdad para su ejercicio. Por ello, el legislador estatuyente no se encuentra limitado por una atribución competencial general del desarrollo del derecho fundamental a la igualdad por parte del Estado. En consecuencia, siempre que exista un título competencial sobre una materia determinada y la misma no suponga desarrollar un derecho fundamental reservado a la Ley Orgánica (sobre estos derechos volvemos en el epígrafe siguiente), la CAA podrá, si así lo decide, regular el modo en el cual el derecho constitucional a la igualdad se debe respetar en la Comunidad Autónoma en ese campo concreto de competencia autonómica. En algunos casos, los que el Estatuto menciona a lo largo de su Título I, esa regulación ha devenido una obligación estatutaria, como consecuencia del mandato de aprobación de las "correspondientes leyes de desarrollo" (art. 38 EAA) que se proyecta sobre todos estos derechos.

Se podrían incluir en este grupo el derecho a la "igualdad de oportunidades entre hombres y mujeres" (art. 15 EAA); Y los derechos de acceso "en condiciones de igualdad" a las prestaciones del sistema público de servicios sociales (art. 23.1 EAA); a las viviendas de promoción pública y a las ayudas para las mismas (art. $25 \mathrm{EAA}$ ); al empleo público (art. $26 \mathrm{EAA}$ ); al disfrute de los recursos naturales, del entorno y del paisaje (art. $28 \mathrm{EAA}$ ); y a la cultura y al disfrute de los bienes patrimoniales, artísticos y paisajísticos (art. 33 EAA).

En todos estos casos nos encontramos con un derecho estatutario a la igualdad cuyo contenido se concreta en poder exigir al legislador autonómico que acometa su regulación. Una regulación, va de suyo, que deberá respetar también el derecho fundamental a "la igualdad ante la Ley" del art. 14 CE, pero sólo cuando sus titulares según la Constitución - "los españoles" - sean también los destinatarios de la norma. En el caso de los extranjeros que sean titulares de estos derechos estatutarios (ver más atrás) el canon de igualdad se- 
rá exclusivamente el que pueda deducirse del Estatuto, salvedad hecha de lo que el Estado pueda haber regulado con carácter básico en virtud de otros títulos competenciales como "extranjería" o "inmigración" ${ }^{20}$.

Pero el Estatuto no contiene tan sólo las concreciones del derecho constitucional a la igualdad que se acaban de mencionar, cada uno de ellos susceptible de regulación en virtud del correspondiente título competencial ${ }^{21}$. Incluye igualmente, como también hace el art. $14 \mathrm{CE}$, su propia cláusula antidiscriminatoria. Esta se establece en el art. 14 EAA, según el cual

"Se prohíbe toda discriminación en el ejercicio de los derechos, el cumplimiento de los deberes y la prestación de los servicios contemplados en este Título, particularmente la ejercida por razón de sexo, orígenes étnicos o sociales, lengua, cultura, religión, ideología, características genéticas, nacimiento, patrimonio, discapacidad, edad, orientación sexual o cualquier otra condición o circunstancia personal o social. La prohibición de discriminación no impedirá acciones positivas en beneficio de sectores, grupos o personas desfavorecidas"

Nos detendremos ahora en analizar las diferencias entre el art. 14 EAA y el art. $14 \mathrm{CE}$ y la relación entre ambos. Las diferencias son tres: en primer lugar, el art. 14 EAA tiene un ámbito menor; en segundo lugar, menciona diferentes criterios específicos de discriminación prohibida; $y$, en tercer lugar, incluye en la propia disposición las medidas de acción positiva. A ello habría que añadir que, como ocurría con las concreciones de la cláusula de igualdad, los sujetos activos del derecho a no ser discriminado no son sólo, como en la CE, "los españoles" sino, al igual que en el resto de derechos de este Título (ver más atrás), todas las personas que cumplan los requisitos establecidos en el art. 12 EAA. Veamos brevemente cada uno de estos aspectos.

\footnotetext{
${ }^{20}$ Ambos en el art. 1491.2 CE. De mayor dificultad sería la aplicación del título horizontal del art. 1491.1 ${ }^{\circ} \mathrm{CE}$, ya mencionado anteriormente, que se limita a habilitar al Estado "para regular las condiciones básicas que garanticen la igualdad de todos los españoles en el ejercicio de los derechos y en el cumplimiento de los deberes constitucionales" (cursiva añadida).

${ }^{21}$ Respectivamente, para la igualdad de oportunidades entre hombres y mujeres, art. 73 EAA; para un sistema público de servicios sociales, art. $61 \mathrm{EAA}$; para las viviendas de promoción pública, art. 56 EAA; para el empleo público, art. 75 EAA; para el disfrute de los recursos naturales, del entorno y del paisaje, art. 57 EAA; y para la cultura y el disfrute de los bienes patrimoniales, artísticos y paisajísticos, art. 68 EAA.
} 
Con respecto al ámbito en el que la discriminación se prohíbe, éste se reduce al "ejercicio de los derechos, el cumplimiento de los deberes y la prestación de los servicios contemplados en este Título". De modo que el estatuyente ha reducido la cláusula antidiscriminatoria a la que pueda darse con ocasión del ejercicio de derechos, del cumplimiento de deberes o de la percepción de prestaciones, siempre que - y sólo cuando - se trate de derechos, prestaciones o deberes del Título I EAA. El ámbito no es, por lo tanto, tan amplio como el contemplado por el art. $14 \mathrm{CE}$, cuya interdicción de discriminación se proyecta sobre cualquier situación jurídica, ya que ordena, con un carácter más genérico, que no pueda "prevalecer ninguna discriminación" entre los españoles "ante la ley".

La cláusula estatutaria incluye, ahora al igual que la cláusula constitucional, una serie de criterios específicos de discriminación. Los contemplados constitucionalmente (nacimiento, raza, sexo, religión y opinión) se encuentran también en el Estatuto (si bien se dice "orígenes étnicos" en lugar de "raza" e "ideología" en lugar de "opinión"). Pero a ellos se suman otros: orígenes sociales, lengua, cultura, características genéticas, patrimonio, discapacidad, edad u orientación sexual. Al terminar también la disposición estatutaria, como la constitucional, con una cláusula abierta - "cualquier otra circunstancia personal o social” - debe entenderse que la función de estos criterios específicos es, como en la CE, reforzar la presunción de discriminación cuando con base en ellos se establezca un trato desigual. Pero, con respecto de la función de estos criterios "altamente sospechosos" en el Estatuto deben tenerse en cuenta las precisiones que se hacen a continuación.

Y es que el art. 14 EAA incorpora, en la propia disposición en la que prohíbe la discriminación, una aclaración: que la misma no impedirá "acciones positivas en beneficio de sectores, grupos o personas desfavorecidas". Esta incorporación tiene, al menos, dos consecuencias para la correcta interpretación de esta norma: en primer lugar, aunque no llega a establecer un "derecho al trato desigual", puesto que las acciones positivas sólo se encuentran "no impedidas", éste no encuentra su fundamento en una norma distinta, actuando por lo tanto como un límite externo al derecho a no ser discriminado (del modo en que interactúan los arts. 14 y $9.2 \mathrm{CE}$ ), sino que su posibilidad forma parte del mismo derecho que se establece, pasando por lo tanto a ser elemento definidor del mismo o, si se quiere, límite "interno". La segunda consecuencia es que el sentido de las cláusulas "altamente sospechosas" que incluye el Estatuto podría llegar a ser en cierto modo el inverso del de las cláusulas que menciona la Constitución: las cláusulas del Estatuto serian aquéllas en virtud de las cuales el estatuyente ha querido delimitar los "grupos, sectores o personas" más desfavorecidos a los que se refiere. De modo que, de cri- 
terios con base en los cuales difícilmente se podría justificar un trato desigual, como ocurre en la Constitución, pasan ahora a ser, precisamente, los criterios con respecto a los cuales más legitimado estaría el legislador autonómico para establecerlos.

Las dificultades de articulación entre el art. $14 \mathrm{CE}$ - al que, huelga decirlo nuevamente, se encuentra vinculado tanto el legislador como el resto de los poderes públicos autonómicos - y el art. 14 EAA son evidentes y provienen del complicado juego combinatorio que abren sus diferentes normaciones sobre titulares, ámbito y cláusulas antidiscriminatorias específicas. Imaginemos por ejemplo, el caso de un extranjero (que no es titular del derecho del art. 14 $\mathrm{CE}$ ) que se queja de la discriminación positiva por razón de edad (criterio no contemplado por la Constitución, pero sí por el Estatuto) que beneficia a un nacional pero no a él en el ejercicio de su derecho estatutario de acceso a la vivienda de promoción pública (establecido en el art. $25 \mathrm{EAA}$ ). O, en un sentido inverso, la queja de un nacional (titular de ambas cláusulas antidiscriminatorias) al que se discrimina por razón de la lengua (criterio "altamente sospechoso" sólo en el Estatuto) en una norma autonómica que regula las condiciones de igualdad ante la ley (art. $14 \mathrm{CE}$ ) en una materia distinta de los derechos contemplados en el Título I del Estatuto (extramuros, por lo tanto, del campo de aplicación del art. 14 EAA). Sólo la jurisprudencia y la construcción doctrinal del encaje entre derechos constitucionales y estatutarios podrán en el futuro ir proporcionando una respuesta a casos como estos.

\subsection{Normas que añaden un contenido estatutario a derechos constitucionales}

Como es doctrinal y jurisprudencialmente pacífico, las CCAA podrán atribuirse capacidad normativa, sin perjuicio de las funciones encomendadas a la Ley Orgánica por la reserva del art. 81.1. CE, sobre aquellos derechos fundamentales o libertades públicas cuya regulación se le haya encomendado por un título competencial autonómico. En función de este criterio, la CAA se encuentra habilitada por su Estatuto para regular todas aquellas modalidades del derecho que caen bajo su ámbito competencial, entendiendo esta normativa no como una regulación del derecho en abstracto, "en cuanto tal" sino de la "materia" sobre la que el derecho se proyecta (STC 173/1998, fj 7). En función del correspondiente título competencial, la regulación de estos derechos podría tener un alcance general, en el sentido de disciplinar en una sola norma todas las modalidades de ejercicio del derecho que caigan bajo su ámbito competencial. En otras ocasiones, las limitaciones de la asunción competencial habilitarán a la CA sólo para una regulación sectorial del derecho, la afectada por la materia objeto de la competencia. 
Pues bien, en todos los casos en los que la CAA se encuentre habilitada, en estos términos, para regular el ejercicio de un determinado derecho constitucional en la Comunidad Autónoma y el Estatuto haya contemplado a su vez un derecho estatutario sobre el particular, la normativa de desarrollo autonómico tendrá que respetar no sólo lo dispuesto constitucionalmente y la reserva del art. 81.1. CE, sino también el contenido estatutario propio de ese derecho. En virtud de los títulos competenciales respectivos, podríamos decir que el Estatuto habilita al legislador autonómico para regular con carácter general el ejercicio en la CAA de una serie de derechos fundamentales que analizamos a continuación, pero en todos esos casos deberá respetar también el correspondiente derecho estatutario.

Un caso especial es el del régimen autonómico de las asociaciones. Existe efectivamente un título competencial que cubre la "materia" sobre la que el derecho se proyecta, y permite por lo tanto la regulación general de la misma. Pero no se ha contemplado como tal un derecho estatutario de asociación, por lo que debe deducirse que el estatuyente ha decido no añadir un contenido estatutario a este derecho, de modo que, al acometer su regulación, el legislador autonómico estará vinculado exclusivamente por lo dispuesto en sede constitucional (y, claro es, por el legislador orgánico), sin que el Estatuto le imponga ningún contenido propio en esta materia.

Efectivamente, la CAA tiene estatutariamente atribuida la competencia exclusiva sobre "el régimen jurídico de las asociaciones que desarrollen principalmente sus funciones en Andalucía”, especificándose que la misma se ejercerá "respetando las condiciones básicas establecidas por el Estado para garantizar la igualdad en el ejercicio del derecho y la reserva de ley orgánica" (art. 79.1 EAA). Y son éstas, las derivadas del art. 22 CE, las únicas prescripciones a las que se vincula la CAA en materia de derecho de asociación, puesto que el estatuyente no lo ha contemplado como derecho estatutario, de modo que no existe ninguna vinculación adicional que hubiera de respetar la ley autonómica que establezca el régimen jurídico asociativo.

Esto no quiere decir que el legislador autonómico, a la hora de acometer el régimen asociativo en la CAA, no pueda otorgar determinados derechos subjetivos a sus destinatarios, pero estos derechos, con exclusivo fundamento en la ley de la CAA, carecerían del rango y los efectos propios de los derechos estatutarios. 


\section{El derecho estatutario de participación política}

Ya con el Estatuto de 1981, y por mandato del art. 147 CE, la CAA tenía un título competencial exclusivo sobre "organización y estructura de sus instituciones de autogobierno" (art. 13.1 EAA 1981), que se completaba luego con otro de "normas electorales para la constitución de sus instituciones de autogobierno" (art. 13.5 EAA). Estas competencias se han mantenido en el Estatuto vigente (pero agrupándolas en una sola disposición, el art. 46 EAA) con la misma dicción literal y añadiendo a la segunda "en el marco del régimen electoral general". Debe considerarse que el contenido de este título competencial no es otro que el desarrollo autonómico del derecho fundamental de participación en los asuntos públicos (art. $23 \mathrm{CE}$ ).

Con el Estatuto de 2007, la CAA se encuentra ahora limitada en el desarrollo normativo de esta competencia no sólo por lo dispuesto por esa disposición constitucional y por el legislador orgánico, sino por lo preceptuado por el nuevo derecho estatutario a la participación política contemplado en el art. 30 EAA. De este modo, la legislación autonómica tendrá que, necesariamente, respetar lo estipulado por los diversos apartados del art. 30 EAA cuando desarrolle en el ámbito competencial de la CAA las dos modalidades de ejercicio del derecho fundamental a la participación que contiene el art. 23 CE, a saber, la participación a través de representantes y la participación directa.

En cuanto a la participación a través de representantes, la disposición estatutaria contempla un derecho "a elegir a los miembros de los órganos representativos de la Comunidad Autónoma y a concurrir como candidato a los mismos" (art. 30.1.a EAA); En cuanto a su objeto, la dicción es deficiente, ya que el plural empleado - "órganos representativos" - podría hacer parecer que entra dentro de este derecho el sufragio activo o pasivo para la elección de una serie de órganos que el Estatuto contempla, precisamente, bajo la denominación de otras "instituciones de autogobierno", y cuya composición se remite en casi todos los casos (salvo en el del Defensor del Pueblo, del que se dice que será elegido por el Parlamento) a lo que diga la Ley. Es claro que ninguna de estas leyes (las que regulan la composición del Consejo Consultivo, el Consejo Económico y Social, el Consejo Audiovisual y la Cámara de Cuentas) contravendrá el art. 30 EAA cuando desconozca el supuesto derecho de los andaluces a votar su composición y a concurrir a ellos como candidatos, pero, por ello, habría sido más claro reducir el derecho estatutario de sufragio al único "órgano de autogobierno" que tiene carácter electivo, el Parlamento de la Comunidad Autónoma. 
El art. 30 EAA no añade nada sobre el régimen electoral, pero sí lo hacen otras disposiciones estatutarias: el art. $104 \mathrm{EAA}$, que concreta quienes son electores y elegibles ("todos los andaluces y andaluzas mayores de dieciocho años que estén en pleno goce de sus derechos políticos"), establece la circunscripción provincial y ordena que la elección se realice "atendiendo a criterios de representación proporcional", pero omitiendo ahora la obligación anterior de que fuera el mismo sistema que el que rija para el Congreso de los Diputados (art. 28.2 EAA 1981). En todo lo demás, el Estatuto remite a la Ley electoral, que según el art. 105 EAA deberá aprobarse por mayoría absoluta del Parlamento y "establecer criterios de igualdad de género para la elaboración de las listas electorales". Como se sabe, el legislador orgánico de la LOREG ha regulado con carácter básico algunos de estos elementos del régimen electoral ${ }^{22}$.

Las modalidades de ejercicio del art. $23 \mathrm{CE}$ que suponen una participación "directa" ${ }^{3}$ en los asuntos públicos y que se consagran como derechos estatutarios en el art. 30 EAA son varias. Sólo una de ellas, sin embargo, puede fundamentarse de forma directa en el título competencial de organización de las instituciones de autogobierno, y es la que da rango de derecho a "promover y presentar iniciativas legislativas ante el Parlamento de Andalucía y participar en la elaboración de las leyes, directamente o por medio de entidades asociativas, en los términos que establezca el Reglamento del Parlamento" (art. 30.1.b EAA).

Esta disposición encierra, en realidad, dos derechos estatutarios diferentes: el de iniciativa legislativa y el de participación en el resto del procedimiento legislativo. Debe entenderse que la remisión al Reglamento del Parlamento se aplica sólo al segundo de ellos, ya que la materia del primero - la promoción y presentación de iniciativas legislativas populares - permite su regulación mediante $\mathrm{Ley}^{24}$.

${ }^{22}$ Así, en cuanto a los criterios de igualdad de género en las candidaturas, ver la modificación introducida en la LOREG por la disposición adicional segunda de la Ley Orgánica 3/2007, de 22 de marzo, para la igualdad efectiva de mujeres y hombres.

23 Este es el término -"directamente" - que usa el art. 23 CE. En realidad, sería más propio hablar de "semidirecta", ya que en cualquier caso los "representantes" intervienen en el proceso.

24 Como efectivamente se hizo bajo la vigencia del Estatuto de 1981, con la aprobación de la Ley 5/1988 de Iniciativa Legislativa Popular y de los Ayuntamientos. 
Para la regulación del resto, que, precisamente, suponen dotar a los ciudadanos de instrumentos participativos al margen de las instituciones de autogobierno, es preciso encontrar otro título competencial, que no es otro que el de "consultas populares" establecido en el art. 78 EAA.

Esta disposición atribuye a la Junta de Andalucía la "competencia exclusiva" para el "establecimiento del régimen jurídico, las modalidades, el procedimiento, la realización y la convocatoria", tanto "por ella misma como por lo entes locales en el ámbito de sus competencias" de "encuestas, audiencias públicas, foros de participación y cualquier otro instrumento de consulta popular, con la excepción del referéndum".

La disposición estatuaria sobre "consultas populares" establece, en realidad, dos regímenes competenciales diferentes: las consultas cuya regulación autonómica, por ser expresión del art. $23 \mathrm{CE}$, se encuentran subordinadas a lo que disponga el legislador orgánico y las que, por no poder incluirse en este derecho fundamental, permiten que la CA las regule en toda su extensión. Aunque el art. 78 EAA se refiere expresamente sólo a las segundas ("encuestas, audiencias públicas, foros de participación"), la cláusula final de "cualquier otro instrumento" permite también incluir a las primeras.

Ahora bien, en relación con las consultas populares que pueden considerarse modalidades de ejercicio del derecho fundamental de participación del art. 23 CE (las otras, no sometidas a reserva de Ley Orgánica, se ven más adelante), el Estatuto ha consagrado como derecho estatutario la promoción de la convocatoria de referendos, que debe considerarse incluida en el derecho a "promover la convocatoria de consultas populares por la Junta de Andalucía o por los Ayuntamientos" al que se refiere el art. 30.1.c EAA. Así lo confirma el art. 117.4 EAA que atribuye al presidente de la Junta la potestad para proponer "la celebración de consultas populares en el ámbito de la Comunidad Autónoma", tanto en materias autonómicas como locales, "por iniciativa propia o a solicitud de los ciudadanos". Los ciudadanos, al cursar esa "solicitud" estarían pues ejerciendo el derecho estatutario de promoción de consultas.

Una vez aclarada la existencia de ese derecho, y la atribución presidencial para su tramitación, resulta, sin embargo, más complicado encontrar un título competencial que habilite a la CA para regular el referéndum autonómico. Ello es así porque la disposición que lo contiene, como se ha visto el art. 78 EAA, le atribuye esta competencia con la excepción expresa del mismo. Es necesario precisar que la CE impide atribuir a las CAA la "autorización de la convocatoria de consultas populares por vía de referéndum”, pues la misma se 
considera una competencia exclusiva del Estado (art. 149.1.32 ${ }^{\circ}$ CE). Pero nada habría impedido que, salvada la autorización de la convocatoria por el Estado, la regulación del referéndum autonómico hubiera sido competencia de la CA. Al no permitirlo el art. $78 \mathrm{EAA}$, habrá que estar a lo que disponga el legislador de la Ley Orgánica de las diferentes modalidades de Referéndum, si bien éste no ha contemplado aún el referéndum de alcance autonómico. Mientas tanto, la promoción de referendos autonómicos debe considerarse, a falta de título competencial autonómico para acometer su regulación, un derecho estatutario de imposible ejercicio, que queda diferido a lo que en su caso decidan, mediante Ley Orgánica, las Cortes Generales.

Finalmente, el art. 30.1 d EAA establece "el derecho de petición individual y colectiva, por escrito, en la forma y con los efectos que determine la Ley" con una dicción literal idéntica a la que recoge el art. 29.1 CE.

\section{Las garantías estatutarias de la libertad de expresión}

Como se sabe, al regular la libertad de expresión ${ }^{25}$, el art. 20 CE establece varias garantías de este derecho fundamental en relación con los medios de comunicación, entre ellas el control parlamentario de los que dependen de cualquier ente público y el derecho de acceso a los mismos de los grupos sociales y políticos significativo. Ambas pueden ser objeto de desarrollo por las CCAA si se atribuyen la competencia de desarrollo de la normativa básica estatal sobre prensa, radio, televisión y, en general, todos los medios de comunicación social que les permite el art. 149.1.27ํㅡ. CE. Éste es el caso del EAA, cuyo art. 69 atribuye las correspondientes competencias a la CAA, si bien diferenciando, lo que no está exento de problemas, entre competencias compartidas, - ordenación, regulación y control de cualesquier medio audiovisual en Andalucía - y exclusivas - sobre organización del servicio público audiovisual andaluz.

En cualquiera de ambos casos, la normativa autonómica al respecto tendrá que respetar las garantías del art. $20 \mathrm{CE}$ y su desarrollo por el legislador orgánico. Y, además, lo prescrito por el propio Estatuto, que, junto con toda una serie de principios programáticos sobre el particular, añade, por un lado, y en cuanto al derecho de acceso, que éste se extenderá no sólo a grupos so-

25 Empleamos aquí el término "libertad de expresión" en un sentido amplio, que cubre tanto lo que el TC denomina "libertad de información" como "libertad de expresión en sentido estricto". 
ciales y políticos significativos, sino también a las organizaciones e instituciones y, por otro, en cuanto al control parlamentario de los medios públicos, la elección directa por el Parlamento del director de la radiotelevisión andaluza y la del director de los medios públicos locales por el pleno de la respectiva corporación.

¿Se trata, en ambos casos, de "derechos estatutarios" que la ley autonómica tendrá que respetar? La duda surge al haberse incluido en el Estatuto en disposiciones que no forman parte del Título I del mismo, sino de un título específico, el VIII, sobre "medios de comunicación social". La elección de un criterio topográfico - los "derechos reconocidos en el presente Título" - a la hora de establecer la vinculación a los mismos por parte de los poderes públicos (ver más adelante) impediría, en principio, considerarlos parte de un derecho estatutario de libertad de expresión que el Estatuto no contempla sino, a lo más, garantías estatutarias de la libertad de expresión constitucionalmente protegida. En todo caso, su ubicación fuera del Título I EAA no las despoja de su condición de normas estatutarias, por lo que deberán ser respetadas con ese carácter por la legislación autonómica de desarrollo.

\section{El derecho estatutario a la protección de datos personales}

Según el art. 32 EAA, "se garantiza el derecho de todas las personas al acceso, corrección y cancelación de sus datos personales en poder de las Administraciones públicas Andaluzas". Mediante este derecho se da pues rango estatutario al derecho fundamental a la protección de datos del art. 18.4 CE. El título competencial para su regulación se encuentra en el art. 82 EAA, que atribuye a la CAA la "competencia ejecutiva" para la protección de los datos personales "gestionados por las instituciones autonómicas de Andalucía, la Administración autonómica, Administraciones locales, y otras entidades de derecho público y privado dependientes de cualquier de ellas, así como por las universidades del sistema universitario andaluz".

Como en los casos precedentes, la extensión del título competencial da la medida en la cual la CAA puede abordar la normación del derecho estatutario a cuyo respeto se ha vinculado. La primera precisión a hacer en este caso es que la competencia atribuida es sólo ejecutiva, con lo que queda excluida la posibilidad de una normación general del derecho, que por prescripción del art. 38 EAA debería ser, en todo caso, por ley. En consecuencia, el contenido estatutario del derecho se reduce a las facultades que el propio Estatuto enumera de "acceso, corrección y cancelación" de los datos. Al ser éste, igualmente, el contenido decidido por el legislador orgánico que ha desarrollado 
el art. 18.4 CE, al trasponer la directiva comunitaria sobre protección de datos, puede decirse que nada aporta, en cuanto al mismo, el derecho autonómico $^{26}$. Cuestión distinta es el despliegue de funciones ejecutivas - también de normación, pero reducidas a lo permitido por el art. 42.3 EAA - sobre la materia, pudiendo pues regular la CAA los procedimientos para poder ejercer esas facultades, las eventuales sanciones para su vulneración, etc. Sobre las mismas, cabría hacer dos observaciones.

En primer lugar, contrastando con el amplio elenco de entidades públicas incluidas en este título competencial, quedan fuera de las potestades ejecutivas autonómica los datos gestionados por entidades privadas (no, ya se ha visto, los gestionados por entidades de derecho privado dependientes de las administraciones). Esto implica que las entidades privadas domiciliadas en Andalucía que gestionen estos datos quedarán vinculadas exclusivamente a lo que disponga la legislación estatal, debiendo respetar, eso sí, los derechos de acceso, corrección y cancelación, y quedando sujetas al procedimiento de inspección y sanción correspondiente, pero por así disponerlo la Ley Orgánica de Protección de Datos (LOPD) y su desarrollo reglamentario, no el Estatuto o las normas autonómicas.

En segundo lugar, el ejercicio de las competencias estatutarias exigirá el establecimiento en el ámbito de la CAA de una "autoridad independiente", en los términos de la Directiva Comunitaria ${ }^{27}$, contempladas también por la LOPD ${ }^{28}$. La creación, por lo tanto, de una Agencia andaluza de Protección de Datos debe considerarse presupuesto necesario para el ejercicio de estas competencias.

\footnotetext{
${ }^{26}$ Ver arts. 13 y ss. de la Ley Orgánica 15/199, de Protección de Datos de Carácter Personal, la norma española de transposición de la Directiva 95/46/CE, del Parlamento Europeo y del Consejo, de 24 de Octubre de 1995, relativa a La Protección de las Personas Físicas en lo que respecta al Tratamiento de Datos Personales y a la libre circulación de estos datos.

${ }^{27}$ Arts. 28.1 de la Directiva 95/46/CE: "Los Estados miembros dispondrán que una o más autoridades públicas se encarguen de vigilar la aplicación en su territorio de las disposiciones adoptadas por ellos en aplicación de la presente Directiva. Estas autoridades ejercerán las funciones que les son atribuidas con total independencia”.

28 Art. 41.1 LOPD, según el cual determinadas funciones de la Agencia de Protección de Datos estatal "serán ejercidas, cuando afecten a ficheros de datos de carácter personal creados o gestionados por las Comunidades Autónomas y por la Administración Local de su ámbito territorial, por los órganos correspondientes de cada Comunidad, que tendrán la consideración de autoridades de control, a los que garantizarán plena independencia y objetividad en el ejercicio de su cometido".
} 
El derecho estatutario a la declaración de voluntad vital anticipada y a la dignidad en el proceso de muerte

El art. 20 EAA establece, en cada uno de sus dos apartados, derechos estatutarios diferentes: el primero, el derecho a "declarar la voluntad vital anticipada"; el segundo, el derecho a "la plena dignidad en el proceso de su muerte" ${ }^{29}$. Ambos se deben considerar manifestaciones del denominado "derecho a la muerte" o derecho a disponer de su propia vida, que podría encontrar su fundamento en algunos de los apartados del art. $15 \mathrm{CE}$.

La CAA no tiene ningún título competencial que le habilite para regular el derecho a la vida del art. $15 \mathrm{CE}$, pero sí posee uno cuyo desarrollo puede afectar determinadas modalidades de su ejercicio. Se trata de la competencia sobre "salud, sanidad y farmacia" del art. 55 EAA, cuyo apartado segundo le atribuye la competencia compartida con el Estado en "sanidad interior" y en particular "la ordenación, planificación, regulación y ejecución de los servicios y prestaciones sanitarias (...)". Es en este ámbito de ordenación que la CAA deberá contemplar lo regulado como derecho de los andaluces en el art. 20 EAA.

Ambos derechos estatutarios - a declarar la voluntad anticipada y a una muerte digna - deben pues considerarse prestaciones sanitarias y probablemente podrían haberse incluido entre las que se asocian al derecho estatutario a la salud (ver más adelante). La justificación de una consideración diferenciada es, a nuestro juicio, doble: en primer lugar, para darle el grado de visibilidad exigible dada su especificidad dentro de las prestaciones que el sistema sanitario debe proporcionar; $y$, en segundo lugar, porque, precisamente, se tratan de prestaciones que pueden directamente afectar al art. $15 \mathrm{CE}$, que según la jurisprudencia constitucional abarca no sólo el "derecho" a la vida sino también la vida humana como bien constitucionalmente protegido.

\section{El derecho estatutario a la educación}

El mismo esquema podría aplicarse, ahora, al derecho estatutario a la educación. En efecto, la CAA no ostenta un título competencial que le faculte directamente para desarrollar el derecho fundamental a la educación cons-

\footnotetext{
${ }^{29}$ Junto con éste último, también el derecho al adecuado tratamiento del dolor y a los cuidados paliativos, que analizamos en relación con el derecho a la salud, ver más adelante.
} 
titucionalizado en el art. $27 \mathrm{CE}$. Pero sí ha asumido competencias sobre esta materia, exclusivas, compartidas o ejecutivas, según la submaterias, y tanto en enseñanza no universitaria (art. 52 EAA) como universitaria (art. 53 EAA). Inevitablemente, el ejercicio de estas competencias afecta al derecho fundamental a la educación, que la CAA tenía ya que respetar, claro es, antes de la aprobación del Estatuto de 2007. Ahora, además, se vincula al respeto de una serie de prestaciones que el nuevo Estatuto ha agrupado en el art. 21 EAA como derecho estatutario a la educación. Muchas de ellas ya se encuentran en el propio art. $27 \mathrm{CE}$ o han sido desarrolladas en el mismo sentido por el legislador orgánico, así que sobre las mismas poco o nada puede añadir el Estatuto en forma de derechos. Otras prestaciones, sin embargo, sí tienen una naturaleza exclusivamente estatutaria, como el derecho de acceso en condiciones de igualdad a todos los centros sostenidos con fondos públicos (art. 21.3 EAA), que deberá reflejarse en los correspondientes criterios de admisión de alumnos (competencia compartida con el Estado según el art. 52.2 EAA); la gratuidad de la educación infantil (sobre la que tiene competencia exclusiva según el art. 55.1 EAA) o la gratuidad de los libros de texto en las etapas obligatorias en todos los centros sostenidos con fondos públicos [ya que ostenta competencia exclusiva sobre "régimen de (...) ayudas [al estudio] con fondos propios, art. 52.1 EAA].

Junto a estas prestaciones, el art. 21 EAA contempla también una serie de mandatos al legislador que, habilitado para ello por el correspondiente título competencial, deberá respetar a la hora de acometer el diseño de los planes educativos (competencia compartida con el Estado) o de las enseñanzas específicas de la CA (competencia exclusiva).

Por último, no es fácil discernir si el derecho estatutario a la educación difiere en algo del modelo constitucional en cuanto a la presencia de la Iglesia Católica en el sistema educativo. Hay, a este respecto, tres datos normativos que dan la medida en la cual el estatuyente ha optado por un modelo que podría añadir algo al de la $\mathrm{CE}$, al cual estaría, obviamente, supeditado: en primer lugar, una novedad absoluta con respecto al art. $27 \mathrm{CE}$, la proclamación de que "[1]a enseñanza pública conforme al carácter aconfesional del Estado, será laica". En segundo lugar, la reproducción en sede estatutaria, con idéntico tenor literal, de la cláusula constitucional que establece el derecho de los padres para que sus hijos reciban la formación religiosa y moral que esté de acuerdo con sus convicciones. Y, en tercer lugar, la reproducción en el art. 21 EAA, se supone que con la vocación de que vincule al legislador educativo autonómico, de la cláusula del art. 16 CE sobre la cooperación con la Iglesia católica pero alterando su dicción literal. Así, donde la CE dice que los poderes 
públicos "tendrán en cuenta las creencias religiosas de la sociedad española y mantendrán las consiguientes relaciones de cooperación con la Iglesia Católica y las demás confesiones", el EAA afirma de los poderes de la Comunidad que éstos "tendrán en cuenta las creencias religiosas de la confesión católica y de las restantes confesiones existentes en la sociedad andaluza". Se reproduce, pues, la mención de la Iglesia o confesión católica y de las demás que tengan presencia social como creencias que los poderes públicos deberán "tener en cuenta", pero se omite el mandato constitucional de cooperación con ellas.

\section{Derechos estatutarios relacionados con la administración de justicia}

$\mathrm{El}$ art. 29 EAA incluye tres prestaciones concretas en relación con la administración de Justicia: se trata de la atención a las víctimas, el acceso a la justicia gratuita y la "calidad" de los servicios de la Administración de Justicia. Todos estos derechos deberán ser respetados a la hora de acometer el desarrollo de las competencias cobijadas bajo el título del art. 80 EAA ("Administración de Justicia"). Todas ellas han sido reguladas bajo la vigencia de EAA 1981 por disposiciones de rango reglamentario, que deberán en el futuro tomar la forma de ley aprobada por el parlamento ex art. 38 EAA (ver más adelante).

En cuanto a las prestaciones propias de la justicia gratuita (como la asistencia letrada, pericial o de intérprete), es preciso recordar que se encuentran garantizadas constitucionalmente (como parte del derecho fundamental a la libertad o del derecho fundamental a la tutela judicial efectiva) cuando se produce una privación de libertad o se ve afectado el derecho a la defensa de los acusados en un procedimiento penal. Sólo en estos dos casos, en la medida en que garantiza el derecho a la libertad personal y el derecho de defensa ante el ius puniendi del Estado, estas prestaciones se consideran en nuestro ordenamiento un derecho fundamental indisponible para el legislador, de titularidad universal. En los demás casos, la exoneración de la obligación general de afrontar los costes derivados de estas prestaciones encuentra su fundamento constitucional en el mandato al legislador del art. $119 \mathrm{CE}$, que establece que "la justicia será gratuita cuando así lo disponga la ley y, en todo caso, respecto de quienes acrediten insuficiencia de recursos para litigar".

Es el derecho de acceso a este beneficio el que el art. 29 EAA consagra como derecho estatutario. Como consecuencia, la Comunidad Autónoma deberá regular en una norma con rango de ley las prestaciones concretas asociadas al mismo, pudiendo incluir, de establecerlo así el legislador autonómico, un estándar de protección mayor que el que se desprende de la normativa esta- 
tal, la Ley 1/1996, de Asistencia Jurídica Gratuita (LAJG), que en este caso podría venir dado por la disminución del umbral de renta para tener acceso al mismo $^{30}$.

\section{El derecho estatutario al trabajo}

El art. 26.1 EAA establece el contenido estatutario del derecho al trabajo, constitucionalizado a su vez en el art. 35 CE. Esta disposición constitucional incluye, dentro del derecho-deber de trabajar que atribuye a "todos los españoles", los derechos a la "libre elección de profesión u oficio", a la "promoción a través del trabajo", a la "remuneración suficiente para satisfacer sus necesidades y las de su familia" y a la no "discriminación por razón de sexo" en el ejercicio de estos derechos. A estos contenidos, el art. 26.1 EAA añade el "acceso gratuito a los servicios públicos de empleo", el "acceso a la formación profesional" y "el derecho al descanso y al ocio". Además, se incluye en esta disposición el acceso al empleo público "en condiciones de igualdad y según los principios constitucionales de mérito y capacidad”.

En principio, la CAA podría proyectar sobre estos derechos estatuarios una normación autonómica que regulara por completo su régimen a partir del contenido definido constitucionalmente, toda vez que se trata de derechos constitucionales en los que, al no recaer una reserva de Ley orgánica, la competencia de "desarrollo", respetando su contenido esencial, podría atribuirse al legislador autonómico. Los títulos competenciales en los que debería estar fundamentado ese desarrollo, sin embargo, matizan de manera importante esta afirmación. Hay que tener en cuenta, en primer lugar, que el Estado ostenta competencias exclusivas sobre "legislación laboral; sin perjuicio de su ejecución por las Comunidades Autónomas" (art. 149.1.7º CE). Y que, en consonancia con ello, el EAA permite a la CAA atribuirse "competencias ejecutivas en materia de empleo y relaciones laborales", en el marco de la legislación del Estado (art. 63.1 EAA). De modo que, aunque no venga impedido por el art. $35 \mathrm{CE}$, el desarrollo legislativo de todo lo que, formando parte del mismo, deba considerarse "legislación laboral" compete en exclusiva al Estado.

\footnotetext{
${ }^{30}$ Como por otra parte ya hacía la normativa reglamentaria que desarrolló este derecho bajo la vigencia del EAA de 1981, el Reglamento de Asistencia Jurídica Gratuita de Andalucía, aprobado por Decreto 216/1999, en relación, por ejemplo, con el beneficiario del derecho que venga a mejor fortuna tras el pleito, según se deduce de la comparación de su art. 51 con el art. 45.2 del Reglamento estatal de Asistencia Jurídica Gratuita, aprobado por RD 996/2003, de 25 de julio.
} 
Ello no obsta a que la CAA tenga que ver limitada su actuación en este campo por los derechos que el art. 26.1 EAA contempla. Pero sí impide el desarrollo normativo de los mismos, al menos en la medida en que deba fundamentarse en la competencia de relaciones laborales y empleo, puesto que el art. 38 EAA exige que, en todo caso, su regulación se haga mediante ley, lo que no se compadece con la carencia, ya se ha visto, de competencias legislativas.

No obstante, los derechos reconocidos en el art. 26.1 EAA podrían regularse por el legislador autonómico en la medida en que encontrara otros títulos competenciales que le habilitaran para ello y que atribuyeran a la CAA competencia legislativa sobre el particular. Este podría ser el caso del derecho de acceso a la formación profesional, al amparo de lo establecido en el art. 55.2 EAA. En el resto de los casos, estaríamos ante derechos que la CAA no puede desarrollar, sin que se deba resentir por ello su vinculación a los mismos. Derechos, pues, de contenido exclusivamente estatutario, no legal, en el ámbito de la CAA.

El apartado segundo de este mismo artículo 26 EAA garantiza a los sindicatos y a las organizaciones empresariales "el establecimiento de las condiciones necesarias para el desempeño de las funciones que la Constitución les reconoce". Según lo que se acaba de ver, estas garantías, como el resto, de inexcusable observancia por parte de la CAA, sólo podrán ser reguladas mediante ley en virtud de lo que establezcan títulos competenciales distintos del de empleo y relaciones laborales. Podrían esgrimirse para ello el de asociaciones, cuando "desarrolle principalmente sus funciones en Andalucía” (art. 79.1 EAA) o, en el caso del expreso mandato de este artículo para regular "la participación institucional en el ámbito de la Junta de Andalucía de las organizaciones sindicales y empresariales más representativas en la Comunidad Autónoma" la competencia sobre administraciones públicas andaluzas (art. 47 EAA).

\subsection{Derechos estatutarios que dotan de contenido a los principios rectores constitucionales}

Un número considerable de las disposiciones que consagran derechos en el EAA se refieren a políticas públicas previamente constitucionalizadas como principios rectores de la política social y económica en el capítulo III del Título I CE. Es el caso de los arts. 17 EAA (Protección de la familia), 18 EAA (Menores), 19 EAA (Mayores), 22 EAA (Salud), 24 EAA (discapacidad o dependencia), 25 EAA (vivienda), 27 EAA (consumidores) y 28 EAA (medio ambiente). 
Como es sabido, los principios rectores constitucionales vinculan a todos los poderes públicos, incluido por lo tanto los autonómicos, en el sentido de que tanto la legislación positiva como la práctica judicial y la actuación de los restantes poderes estarán informadas por su "reconocimiento, respeto y protección". Pero estos principios carecen de contenido esencial oponible al legislador, ya que sólo podrán ser alegados ante la Jurisdicción ordinaria "de acuerdo con lo que dispongan las leyes que los desarrollen" (art. 53.3 CE). Estas "leyes" de desarrollo, además, no deben de entenderse en el sentido formal del término, ya que los principios pueden ser desarrollados también por el Estado mediante normas con rango de ley. Pues bien, el EAA, al incluir algunos de estos principios como derechos estatuarios ha introducido, dentro de su ámbito competencial, una triple transformación en los mismos: en primer lugar, los ha dotado de un contenido oponible al legislador autonómico, en segundo lugar los ha sujetado a reserva de ley formal para su desarrollo en todo lo que sea de su competencia y, en tercer lugar, los ha dotado de la protección jurisdiccional que le es propia a todos los derechos del título I EAA (ver sobre todas estas garantías lo que se dice más adelante). Esto ha ocurrido en los siguientes casos:

En relación con el principio rector constitucional que obliga a los poderes públicos a asegurar la "protección social, económica y jurídica de la familia" (art. $39 \mathrm{CE}$ ), el Estatuto exige al legislador autonómico que esta protección contemple un sistema de ayudas a "las diversas modalidades de familia existentes según la legislación civil" (art. 17.1 EAA) y proclama el derecho de las parejas no casadas a "inscribir en un registro público sus opciones de convivencia", registro que dará a estas parejas "los mismos derechos que las parejas casadas" en el ámbito de competencias de la CAA (art. 17.2 EAA).

En el caso del principio rector que la Constitución dedica a las personas mayores ("ciudadanos durante la tercera edad", según el art. $50 \mathrm{CE}$ ), ésta establece para el legislador los mandatos de garantizar la suficiencia económica mediante pensiones adecuadas y periódicamente actualizadas y la promoción de su bienestar mediante un sistema de servicios sociales "que atenderán sus problemas específicos de salud, vivienda, cultura y ocio". Este mandato lo ha recogido el Estatuto estableciendo los derechos a la protección y atención "integral" necesarias para la promoción de su "autonomía personal" y del "envejecimiento activo" y una "asistencia gerontológica adecuada", en los ámbitos sanitario, social y asistencial, y a la percepción de prestaciones (art. 19 EAA). Del mismo modo, el principio rector constitucional que obliga a realizar una política de "previsión, tratamiento, rehabilitación e integración" para con los "disminuidos físicos, psíquicos y sensoriales" y a "ampararlos especialmente" 
en el ejercicio de sus derechos (art. $49 \mathrm{CE}$ ), se ha concretado en el derecho estatutario, del que son titulares las "personas con discapacidad y la que esté en situación de dependencia" a acceder a las ayudas, prestaciones y servicios de calidad "con garantía pública" (art. 24 EAA).

De forma parecida, en cuanto a los consumidores (principio rector del art. $51 \mathrm{CE}$ ), el art. 27 EAA establece ahora como derechos, con una dicción muy próxima a la disposición constitucional, los de asociación, información, formación y protección y se remite a la ley para la regulación de los mecanismos de participación y el catálogo de derechos del consumidor. También en términos muy parecidos al art. $46 \mathrm{CE}$ se pronuncia el art. $28 \mathrm{EAA}$ al establecer el derecho al medio ambiente, si bien éste entra en mayores precisiones en cuanto a los elementos medioambientales sobre los que proyecta su protección y establece como derecho asociado al mismo el acceso a la información medioambiental de la que disponen los poderes públicos (art. 28.3 EAA). Y, en cuanto a vivienda, añade el art. 25 EAA sobre las prescripciones del art. 47 CE la obligación de los poderes públicos a su promoción pública (además, como ya se ha visto, del derecho de acceso en condiciones de igualdad a las ayudas que lo faciliten). Al igual que en todos los casos anteriores, nos encontramos con normas que, en cuanto que establecedoras de derechos, no atribuyen a la CAA competencias para su normación, por lo que habrá que estar a lo que diga el correspondiente título competencial.

Mención aparte merece, por su extenso desarrollo estatutario, el derecho a la salud (art. 22 EAA) con el que el Estatuto da cumplimiento al principio rector constitucional correspondiente. Este (art. 43,1 CE) se limita a reconocer "el derecho a la protección de la salud" y a atribuir a los poderes públicos la organización y tutela de la salud pública "a través de las medidas preventivas y de las prestaciones y servicios necesarios" y a remitir al legislador el establecimiento de "los derechos y deberes de todos al respecto". Por su parte, el Estatuto, garantiza este derecho "mediante un sistema sanitario público de carácter universal” (art. 22.1 EAA), a cuyos usuarios y pacientes atribuye una serie de derechos pormenorizadamente detallados (art. 22.2. EAA), que van desde el acceso a todas las prestaciones del sistema o la libre elección de médico y centro sanitario a la garantía de un tiempo máximo para el acceso a servicios y tratamientos, a la segunda opinión facultativa o la asistencia geriátrica especializada.

$\mathrm{Al}$ igual que en los casos anteriores, habrá que estar al título competencial para precisar el grado en el cual estos derechos podrán ser objeto del correspondiente desarrollo autonómico. Éste podrá fundamentarse bien en la 
competencia exclusiva sobre organización de establecimientos sanitarios (art. 55.1 EAA), bien en la competencia compartida sobre servicios y prestaciones de carácter público (art. 55.2 EAA).

\section{4. "Nuevos" derechos}

Finalmente, el Estatuto contempla, dentro de su tabla de derechos, algunos que no se encuentran presentes en la Constitución, ni bajo la forma de derechos constitucionales ni como principios rectores de la política social y económica y que, en este sentido, podemos calificar de "nuevos". El catálogo de los mismos es bastante amplio, y cubriría, al menos, siete derechos estatutarios: el derecho de las mujeres a la protección integral contra la violencia de género (art. $16 \mathrm{EAA}$ ), el derecho de los menores a la protección y atención integral (art. 18 EAA) y los derechos a la renta básica (art. 23.2 EAA), a la buena administración (art. $31 \mathrm{EAA}$ ), al acceso a las tecnologías de la información (art. $34 \mathrm{EAA}$ ), al respeto a la orientación sexual y a la identidad de género (art. 35 EAA) y a la promoción de las consultas populares que no suponen ejercicio del art. $23 \mathrm{CE}$ (incluido dentro del art. $30 \mathrm{EAA}$ ). Algunos de ellos merecen un comentario más detenido.

Así, en cuanto al derecho de las mujeres a la protección integral contra la violencia de género y el derecho al respeto a la orientación sexual y a la identidad de género, debe enmarcarse en una preocupación más general por las cuestiones de género que se encuentra presente prácticamente a lo largo de todo el Estatuto, que le dedica un buen número de disposiciones. La idea de igualdad de género se proyecta no sólo sobre la situación que pueda tener la mujer a causa de su sexo, sino también sobre cualquier tipo de discriminación que pueda estar causada por el género o la condición sexual de las personas, como se ha visto más atrás al analizar el art. 14 EAA.

En cuanto al desarrollo de estos derechos, hay que tener en cuenta que la cláusula competencial que lo posibilita es la que regula las políticas de género (art. $73 \mathrm{EAA}$ ). Allí se distinguen una serie de competencias que son exclusivas de la Comunidad de otras que se comparten con el Estado. Tienen el carácter de exclusiva las competencias sobre promoción de la igualdad entre hombres y mujeres, en todos los ámbitos, que incluye la posibilidad de dictar normas, tanto propias como de desarrollo de las del Estado, sobre esta materia; la planificación y puesta en marcha de las acciones positivas; y la promoción del asociacionismo de mujeres. Con el carácter de competencia compartida con el Estado se contempla la protección de las mujeres contra la violencia de género, si bien la Comunidad podrá regular servicios y destinar recur- 
sos propios para dispensar una protección integral, y establecer medidas e instrumentos para la detección y prevención de este tipo de violencia y destinadas a la sensibilización de la población.

Otras referencias a la igualdad de género a lo largo del texto estatutario se encuentran en las disposiciones que regulan el empleo (no discriminación por embarazo o maternidad, en el art. 167 EAA; conciliación de la vida familiar y laboral en el art. 168 EAA), la enseñanza, (educación en el valor de la igualdad entre hombre y mujeres en los planes de estudio, en el art. 21.8 EAA), la contratación y subvención pública (igualdad de oportunidades entre hombres y mujeres, en el art. 174.c EAA, o los medios audiovisuales (encomendando a estos velar por la igualdad de género y la eliminación de cualquier forma de discriminación en su programación, en el art. 208 EAA).

Por su parte, el art. 31 EAA garantiza el derecho a una buena administración. Como se sabe, este derecho tiene un precedente europeo: fue la Carta de Derechos de la Unión Europea (CDFUE) el primer texto que lo consagró como derecho fundamental. Es, por lo tanto, legítimo indagar sobre su naturaleza según el derecho comunitario como modo de aventurar cuáles podrían ser los contornos de este derecho según el Estatuto.

El origen del derecho a la buena administración puede cifrarse en el art. 195 TCE, que, al instituir la figura del Defensor del Pueblo Europeo, lo facultaba para recibir "quejas relativas a casos de mala administración en la acción de las instituciones u órganos comunitarios". La actuación del Defensor europeo en este sentido fue obligando a perfilar el concepto de "mala administración", que quedó finalmente definido en su Informe correspondiente al año 1997 del siguiente modo: "se produce mala administración cuando un organismo público no obra de conformidad con las normas o principios a que ha de atenerse obligatoriamente" ${ }^{31}$. Esta definición fue aceptada por el resto de las instituciones de la Unión, y ha sido con base en la misma cómo el Defensor ha venido tramitando las quejas por mal funcionamiento en la administración comunitaria.

Fruto de esa práctica, el art. 41 CDFUE recoge como derecho fundamental el "derecho a la buena administración". Establece, en su apartado pri-

\footnotetext{
${ }^{31}$ Ver DEFENSOR DEL PUEBLO EUROPEO, Informe anual 1997, p. 25.
} 
mero que toda persona tiene derecho a que "las instituciones, órganos y organismos de la Unión traten sus asuntos imparcial y equitativamente y dentro de un plazo razonable”. El apartado segundo del mismo artículo especifica que el derecho a la buena administración incluye también los derechos a ser oído en la toma de decisiones y de acceso al expediente y la obligación de la administración a motivar sus decisiones. El apartado tercero recoge el derecho a la indemnización por daños causados por instituciones o agentes de la Comunidad y el cuarto el derecho a dirigirse a las instituciones de la Unión en alguna de las lenguas del Tratado.

El art. 31 EAA no asocia todas estas facultades al derecho a la buena administración. Lo hace tan sólo en relación con el tratamiento objetivo e imparcial de los asuntos y su resolución en un plazo razonable, a las que añade la participación plena en los asuntos en los que pueda verse afectado cualquier persona, la obtención de una información veraz y la actuación de las administraciones públicas proporcionada a sus fines.

La cercanía del lenguaje empleado para establecer este derecho con algunas de las expresiones que nos son familiares en la construcción del derecho a la tutela judicial efectiva (trato imparcial, plazo razonable) ha servido para resaltar la vis expansiva de la que podría dotarse al derecho a la buena administración si se interpreta en el mismo sentido, trasladando al ámbito administrativo un conjunto de garantías análogas a las que introdujo en su momento, en relación con la justicia, el derecho a la tutela judicial.

La base para desarrollar los diferentes elementos de este derecho sería el

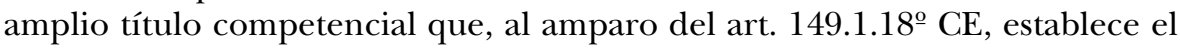
art. 47 EAA. Su desarrollo podría también inspirarse en lo ocurrido en el campo comunitario, en el que el Parlamento Europeo ha aprobado un Código Europeo de Buena Conducta Administrativa, que pretende desarrollar los aspectos concretos del derecho a la buena administración establecido en la CDFUE, dirigido a las instituciones y órganos de la Unión Europea, cuyos contenidos deberán ser respetados por esas administraciones y por sus funcionarios en sus relaciones con los administrados ${ }^{32}$.

Hay, en todo caso, un elemento del derecho estatutario a la buena administración que merece un comentario particular. Se trata del derecho "a ac-

\footnotetext{
32 Código Europeo de Buena Conducta Administrativa, aprobado por el Parlamento Europeo el 6 de septiembre de 2001.
} 
ceder a los archivos y registros de las instituciones, corporaciones, órganos y organismos públicos de Andalucía, cualquiera que sea su soporte, con las excepciones que la ley establezca", que establece el inciso final del art. 31 EAA.

Este derecho también tiene una raíz claramente comunitaria, ya que ha sido la Unión Europea el entorno más próximo a nosotros en el que, en el marco de la denominada "política de transparencia" se ha establecido un derecho de acceso a los documentos de sus instituciones. El origen de este derecho en la Unión, sin embargo, si bien se encuentra relacionado con el derecho a la buena administración, es independiente de éste, y de este modo se ha vertido en la CDFUE. La principal diferencia entre uno y otro derecho estriba en que el derecho a la buena administración se dirige a los administrados, mientras que el derecho de acceso a los documentos es un derecho más general, de todos los ciudadanos. De hecho, la característica más relevante de este derecho es que para ejercerlo no hay que estar directamente afectados por el expediente administrativo al que se pretende acceder.

Pues bien, la consideración por el art. 31 EAA del derecho de acceso a los documentos como una parte del derecho a la buena administración podría conducir a su interpretación como un derecho más de las personas afectadas por un expediente administrativo (y por lo tanto, una simple elevación al Estatuto del derecho que ya concede la ley), desnaturalizando así su naturaleza originaria de derecho de acceso universal. A ello podría contribuir la propia literalidad de esta disposición, que se refiere primero al derecho a los ciudadanos a "participar plenamente en las decisiones [administrativas] que les afecten" (cursiva añadida), añadiendo a continuación "así como a acceder a los archivos y registros (...)".

Aunque habrá que esperar al desarrollo legal y jurisprudencial del derecho estatutario de acceso a los documentos, la importancia que el mismo ha adquirido en el contexto europeo y la diferente ratio del mismo en relación con el derecho a la buena administración, habría merecido sin duda su consagración en una disposición independiente.

Finalmente, nos referimos ahora al derecho a la promoción de consultas populares que no suponen ejercicio del derecho fundamental a la participación en los asuntos públicos del art. $23 \mathrm{CE}$. Como es conocido, la jurisprudencia constitucional ha establecido que no todos los instrumentos de participación que pueda contemplar el ordenamiento suponen un ejercicio de este derecho fundamental. Ya se ha visto que el título competencial para la regulación de estos mecanismos es tan amplio - comprende "audiencias públi- 
cas, foros de participación y cualquier otros instrumento de consulta popular" - que sin duda acoge también esas modalidades que no suponen ejercicio del derecho fundamental. La cuestión a dilucidar es si el art. 30 EAA ha consagrado o no la promoción de algunos de estos instrumentos de participación como un derecho. Es decir, si, a la hora de desarrollar esa competencia el legislador autonómico no podrá desconocer que tiene, por mandato del Estatuto, que hacerlo de modo que no se desconozca el derecho estatutario a promover la celebración de este tipo de consultas. La dicción del art. 30 EAA parece indicarlo así, pues se refiere, en términos igualmente amplios, al "derecho a promover la convocatoria de consultas populares por la Junta de Andalucía o por los Ayuntamientos".

Que - salvados los casos de la iniciativa legislativa popular y del referéndum, como ya se ha visto más atrás - nos encontremos ahora ante derechos estatutarios sobre los que no recae reserva de Ley Orgánica, al no ser, en estas modalidades, ejercicio del derecho fundamental del art. $23 \mathrm{CE}$, tiene dos importantes consecuencias para el régimen estatutario del derecho: la primera de ellas es que la CAA puede regularlo en su totalidad; la segunda, que puede, en este mismo sentido, extender la titularidad del mismo a los extranjeros con vecindad administrativa en Andalucía.

Esta segunda afirmación exige una breve exégesis de los arts. 12 y 30 EAA, únicos relevantes para la cuestión puesto que, como se ha visto, no interviene aquí el legislador orgánico estatal: ya se ha visto que la titularidad genérica de los derechos estatutarios por todos aquellos que tengan vecindad administrativa en la Comunidad Autónoma se excepciona, en el propio art. 22 EAA, en relación con los derechos se participación del art. 30 EAA. Como en su momento se dijo, esta excepción no es sino consecuencia del mandato del art. 13.2 CE. Pero hay ahora que poner de relieve que el mandato constitucional de exclusión de los extranjeros de los derechos de participación (como se sabe, con la excepción, a su vez, del sufragio local) se circunscribe a "los derechos reconocidos en el art. 23". Se impide, pues, ope constitutione, la titularidad por los extranjeros sólo de aquellos derechos del art. 30 EAA que suponen un ejercicio de los derechos del art. $23 \mathrm{CE}$. En el resto - así en las "consultas populares" que analizamos en este epígrafe - la exclusión de los extranjeros trae exclusivamente causa de lo que establece el Estatuto, que la determina, sin el distingo que se deduce de la Constitución, para todas las modalidades de participación establecidas en el art. 30.

Ahora bien, el propio art. 30 EAA contempla en su apartado segundo la posibilidad de que todos los derechos de participación que en él se contem- 
plan se hagan extensivos a los extranjeros, mandatando para este fin a la administración autonómica ${ }^{33}$. La conclusión a la que debe llegarse, pues, es que si bien los extranjeros no son titulares, ex art 12 EAA, de los derechos de participación estatutarios, el art. 30.2 EAA obliga a hacerlos extensivos a los mismos allí donde la Constitución lo permita. Es el caso de todas las consultas populares que no supongan un ejercicio del derecho fundamental del art. $23 \mathrm{CE}$.

\section{DEBERES}

El Estatuto dedica una disposición específica del Título I - el art. 36.1 EAA - al establecimiento de los deberes estatutarios, que se entienden dentro del ámbito competencial de la CAA y sin perjuicio de los deberes constitucionalmente establecidos. Estos deberes estatutarios, cuyo desarrollo se encomienda al legislador, se enumeran en el apartado primero de este artículo, y van desde la contribución al sostenimiento del gasto público o a la conservación del medio ambiente, el uso responsable y solidario de las prestaciones y servicios públicos, la colaboración en la situaciones de emergencia, el cuidado del patrimonio público, la contribución a la educación de los hijos el cumplimiento de la obligaciones derivadas de la participación en la Administración electoral.

El art. 36.2 EAA regula en una disposición específica la obligación por parte de las empresas de ajustarse a los principios de respeto y conservación del medio ambiente que desarrolla el Título VII del propio Estatuto, y encomienda a la Administración autonómica el establecimiento de los correspondientes mecanismos de inspección y sanción.

\section{PRINCIPIOS RECTORES ESTATUTARIOS}

Con independencia de que, como se ha visto, haya elevado a la categoría de derechos estatutarios algunos de los principios rectores de la política social y económica que enumera la Constitución, el Estatuto contiene también su propio catálogo de principios, denominados por el art. $37 \mathrm{EAA}$, único inte-

\footnotetext{
${ }^{33}$ Según el art. 30.2 EAA, "La Junta de Andalucía establecerá los mecanismos adecuados para hacer extensivo a los ciudadanos de la Unión Europea y a los extranjeros residentes en Andalucía los derechos contemplados en el apartado anterior, en el marco constitucional y sin perjuicio de los derechos de participación que les garantiza el ordenamiento de la Unión Europea”.
} 
grante del capítulo III de este Título, "principios rectores de las políticas públicas". La "aplicación efectiva" de los mismos se considera por esta disposición el Instrumento para que las políticas públicas de la Comunidad se orienten a garantizar tanto los derechos estatutarios como los objetivos básicos que, por su parte, establece el art. 10.3 EAA.

El listado tanto de aquellos objetivos básicos (veinticuatro) como de los principios mediante los cuales se alcanzarían (veinticinco) es muy amplio, confundiéndose a veces unos con otros. Por ejemplo, la especial atención o protección a las personas en situación de dependencia (a la vez objetivo básico de la Comunidad en el art. 10.3.15 $5^{\mathrm{o}}$ EAA y principio rector de su política en el art. $37.4^{\circ} \mathrm{EAA}$ ). Por lo demás, el catálogo de principios incluye tanto los propios de los Estados sociales contemporáneos (calidad de los servicios, empleo, concertación social, etc.) como otros más novedosos ligados a nuevos problemas o aspiraciones sociales (lucha contra el sexismo, la homofobia o la xenofobia, envejecimiento activo, discapacidad, integración de inmigrantes, etc.).

No siendo deseable, cara a una mejor distinción entre unos y otros, la confusión entre "objetivos básicos" y "principios rectores", lo es menos la que pudiera producirse entre éstos y los derechos del capítulo II, toda vez que darle una doble presencia en el Estatuto, lejos de redoblar la protección que como derechos se le da, podría reducir ésta a la propia de los principios.

En efecto, como veremos inmediatamente, y de un modo muy parecido a como hace la CE, el Estatuto otorga una protección distinta a derechos y a principios, y establece una vinculación sensiblemente menor de los poderes públicos a estos últimos, sobre todo por parte del legislador, que goza sobre ellos de una amplísima libertad de configuración. Sin embargo, el listado de principios rectores estatutarios del capítulo III sigue mencionando algunos de los tradicionalmente asociados al carácter social del Estado, olvidando que en el capítulo anterior éstos se han protegido mejor - o al menos, con una técnica diferente: la de su oponibilidad frente al legislador y su salvaguardia jurisdiccional - como derechos. Así ocurre en el caso ya mencionado de la "especial protección de las personas en situación de dependencia" (principio rector en al art. 37.1.4 ${ }^{\circ}$ EAA y derecho estatutario en el art. 24 EAA), la plena equiparación laboral entre hombres y mujeres (art. 37.1.11 ${ }^{\circ}$ EAA y art. 15 EAA), el libre acceso de todos a la cultura (art. $37.1 .17^{\circ}$ y art. 33 EAA) o la protección especial a las personas mayores art. 37.1.3 EAA y art. 19 EAA). 


\section{LAS GARANTÍAS}

El capítulo IV del Título I del Estatuto (arts. 38-41 EAA) se dedica a las garantías de los derechos y principios establecidos en los capítulos anteriores. La estructura de este capítulo es muy similar a la del capítulo correspondiente de la Constitución (capítulo IV del Título I, arts. 53 y 54 CE), salvo por el número de disposiciones (cuatro), fruto de la consagración de una disposición específica, al igual que hace la Constitución en el art. $54 \mathrm{CE}$, para el Defensor del Pueblo andaluz (art. 41 EAA) y a la distribución estatutaria en tres artículos (arts. 38, 39 y 40 EAA) de las garantías que establecen los tres apartados del art. 53 CE. El contenido de estas disposiciones se analiza a continuación.

\subsection{Desarrollo de los derechos}

Además de la proclamación de la vinculación de poderes públicos y particulares y del principio interpretativo de favor libertatis (ver más atrás), el art. 38 EAA establece un mandato al Parlamento para el desarrollo de los derechos reconocidos en el capítulo II. En el mismo se establece tanto la reserva de ley autonómica como la exigencia de que la misma respete el contenido de los mismos y determine, en su caso, las prestaciones y servicios vinculados.

En cuanto a la reserva de Ley, hay que tener en cuenta que no todos los derechos estatutarios estaban ya afectados por la misma en su condición de derechos constitucionales: por una parte, la Constitución no obliga, como se sabe, al desarrollo mediante ley de los principios rectores constitucionales del capítulo III del Título I CE, y está obligación tampoco recae, como es evidente, sobre los nuevos derechos que contempla el Estatuto pero no la propia Constitución. Ahora, en el ámbito de competencias de la CAA, las normas de desarrollo de todos los derechos del capítulo II del Título I del Estatuto deben entenderse afectadas por la reserva del art. 38 EAA, que no hace distinciones en función de si se trata de derechos previamente establecidos constitucionalmente. En consecuencia, las normas autonómicas que regulen estos derechos, tanto si están en la Constitución como si no, deben ser leyes aprobadas por el Parlamento.

La dicción literal del art. 38 - "El Parlamento aprobará las correspondientes leyes de desarrollo" - exige concluir que sobre estos derechos recae igualmente una reserva negativa de normas autonómicas con fuerza de Ley, tanto decretos leyes como decretos legislativos, introducidos ex novo en el ordenamiento autonómico por el Estatuto, reformando así el anterior sistema de fuentes. Así lo confirma, por lo demás, el propio régimen estatutario de es- 
tas normas, que excluye de la posibilidad de delegación legislativa, entre otras materias, "las leyes relativas al desarrollo de los derechos y deberes regulados en este Estatuto" e impide que el decreto ley pueda "afectar", entre otros, "a los derechos establecidos en este Estatuto"34. La ley autonómica, no obstante, no deberá aprobarse por mayoría cualificada (art. 108 EAA a contrario), a no ser que así se especifique en el caso correspondiente (como hace el art. 105 EAA con respecto a la Ley electoral, para la que se exige, como se ha visto, mayoría absoluta).

Además, la ley de desarrollo deberá en todo caso respetar el contenido del derecho "establecido por el Estatuto". Esta prevención, cuya similitud con la del "contenido esencial" del art. 53.1 CE es evidente, limita de manera importante la libertad de configuración del legislador, al que se remite con carácter general este art. 38 EAA y con carácter específico un buen número de disposiciones estatutarias, particularmente aquéllas en las que el estatuyente parece haber querido equilibrar la proclamación estatutaria del derecho con la aclaración, a renglón seguido, de que el mismo se ejercerá según disponga el legislador. Así ocurre, por ejemplo, con los "términos, condiciones y requisitos" que la ley debe establecer para poder ejercer los derechos que establecen prestaciones sanitarias (art. 22.4 EAA), con el derecho a recibir de los poderes públicos, en caso de necesidad, una renta básica, "con arreglo a lo dispuesto por la ley" (art. 23.2 EAA), etc.

La remisión al legislador es inevitable dado el carácter prestacional del derecho, y la consecuente exigencia de cierta "cuantificación" de la prestación, que no puede llevar a cabo, por su propia naturaleza, la norma estatutaria. Pero el carácter de derecho subjetivo que el Estatuto ha querido, sin duda, dar a estas prestaciones, otorgándole así una naturaleza sustancialmente distinta a la de los principios rectores, impide dotar de una plena libertad de configuración al legislador, por más que las remisiones a la ley se incluyan en la misma disposición que reconoce el derecho. Más bien, la técnica, que vincula al legislador mismo, del "contenido estatutario" del derecho nos llevan a concluir que éste no podrá ser desconocido, en su esencia, por la ley. Es el Estatuto, y no la ley, quien crea el derecho subjetivo a la prestación y la ley no podrá desconocerla con el pretexto de acometer su regulación.

\footnotetext{
${ }^{34}$ Respectivamente, arts. 109.2 d) y 110.1 EAA. Por otra parte, la similitud en la redacción apuntan a una interpretación de las mismas, al menos en cuanto a su no idoneidad para "desarrollar" o "afectar" a los derechos estatutarios, en un sentido análogo a la de los arts. 82 y 86 CE.
} 
Cuestión distinta es el control que pueda proyectarse sobre la ley autonómica que vulnerara el derecho estatutario al desconocer su contenido. La afirmación tajante - por lo demás innecesaria - del art. 115 EAA que encomienda en exclusiva el control de constitucionalidad de las normas autonómicas con fuerza de ley al Tribunal Constitucional confirma que no se ha previsto ninguna otra posibilidad de control de la ley autonómica vulneradora de derechos estatutarios. Todo lo cual nos conduce a la cuestión, de mayor complejidad teórica, sobre la integración por parte del Estatuto del parámetro de constitucionalidad de las normas autonómicas con fuerza de ley, no ya en cuestiones competenciales, en tanto que parte del bloque de constitucionalidad ex art. 28.1 LOTC, sino también en materia de derechos fundamentales.

Finalmente, el art. 38, como ya se ha mencionado, obliga también a que la ley autonómica determine, en su caso, las "prestaciones y servicios" vinculados al ejercicio del derecho que se desarrolla.

\subsection{Protección jurisdiccional de los derechos}

El art. 39 EAA establece la posibilidad de protección jurisdiccional de los derechos del capítulo II - "los derechos mencionados en el artículo anterior". Sobre la misma, cabe plantear las siguientes cuestiones:

En primer lugar, la instancia y el procedimiento correspondiente, habida cuenta de la remisión estatutaria a "los procedimientos que establezcan las leyes procesales del Estado". En cuanto al órgano judicial competente, pocas dudas deben caber de que, sea cual sea éste, los posibles recursos se agotarían ante el Tribunal Superior de Justicia de Andalucía (TSJA). Debe tenerse en cuenta que el mismo, según el Estatuto, es "la última instancia jurisdiccional de todos los procesos judiciales iniciados en Andalucía, así como de todos los recursos que se tramiten en su ámbito territorial, sea cual fuere el derecho invocado como aplicable" (art. 140.2 EAA), sin perjuicio de la competencia reservada al Tribunal Supremo, que en todo caso debe entenderse conjuntamente con la atribución en exclusiva al TSJA de "la unificación de la interpretación del derecho de Andalucía” (art. 140.3 EAA). El hecho de que se le atribuya igualmente al TSJA la competencia "para tutelar los derechos reconocidos por el presente Estatuto" (art. 140.1 EAA) podría fundamentar la regulación futura en todo caso, como se ha dicho, en una ley del Estado - de un procedimiento especial de defensa que se instara directamente ante el mismo.

En segundo lugar, cabe mencionar que aunque tan sólo en una disposición anterior, el art. $38 \mathrm{EAA}$, se ha establecido la vinculación de los particula- 
res a los derechos estatutarios (ver más atrás) el art. 39 EAA se refiere a la posibilidad de protección jurisdiccional exclusivamente frente a "actos de los poderes públicos de la Comunidad”. Parecería, pues, que el Estatuto no obliga a que este tipo de protección se aplique a eventuales vulneraciones por parte de los particulares. Ahora bien, la ausencia de protección jurisdiccional quebraría en buena medida la proclamación de eficacia inter partes que acaba de hacerse. Al no encontrarse ésta prohibida por la norma estatutaria, es de esperar, con todo, que se recoja en la correspondiente ley procesal. Algo parecido cabría decir de la amplia dicción del sujeto pasivo público de los derechos del art. 38 EAA - "todos los poderes públicos andaluces" - y la aparentemente más restrictiva de este art. $39 \mathrm{EAA}$ - "los poderes públicos de la Comunidad" - que debería pues interpretarse en un sentido amplio, no restringido a la Administración Autonómica.

En tercer lugar, cabe adelantar que la relación entre el procedimiento previsto por el Estatuto para la protección de los derechos estatutarios y los ya existentes para la protección de los derechos constitucionales dará lugar a problemas de interpretación. Particularmente en lo que hace a derechos del Estatuto que son también derechos constitucionales susceptibles de protección mediante el recurso de amparo, es decir, las diferentes manifestaciones del derecho a la igualdad y los derechos de participación en los asuntos públicos y de petición, algunas de las garantías de la libertad de expresión, el derecho de protección de datos personales, el de declaración de la voluntad vital anticipada y a la dignidad en el proceso de muerte y las prestaciones ligadas al derecho a la educación y al de acceso a la justicia. No cabe duda de que la vulneración de todos estos derechos puede llevar aparejada también la vulneración del correspondiente derecho fundamental constitucional, y en ese caso es evidente que se abre la posibilidad del amparo ante el Tribunal Constitucional. Menos claro es, sin embargo, que éste pueda amparar también el contenido exclusivamente estatutario del derecho en cuestión. En la respuesta a esta cuestión habrá que tener en cuenta la doctrina del TC sobre el contenido (meramente) legal - en este caso, estatutario - de los derechos, por una parte, y las disfuncionales tendencias de "forum shopping" a la que las mismas podrían llevar, por otra.

\subsection{Efectividad de los principios rectores}

El tratamiento de los principios rectores de las políticas públicas que se hace en el art. 40.1 EAA es, como se dijo, muy similar al que establece el art. 53.3 CE con respecto a los principios constitucionales rectores de la política social y económica, hasta el punto de que las diferencias entre ambos pueden 
considerarse prácticamente de estilo ${ }^{35}$. Con todo, el Estatuto añade un apartado segundo cuya única justificación podría estar en entender el mandato de reconocimiento y protección no sólo al momento interpretativo propio de los operadores jurídicos sino también a los propiamente políticos, a los que se ordena impulsar la legislación, garantizar la financiación y asegurar la eficacia y eficiencia de las actuaciones administrativas encaminadas a su efectivo cumplimiento.

En todo caso, y a diferencia de lo que ocurre con las normas que establecen propiamente derechos, las normas programáticas de carácter principial ya se encontraban, bajo la forma de "objetivos básicos" de la Comunidad Autónoma, en los once apartados (algunos de ellos reproducidos en el actual) del art. 12.3 del Estatuto de 1981, por lo que cabe remitirse a los estudios que a lo largo de sus años de vigencia se han hecho sobre los mismos. Es posible que sólo la emulación constitucional haya sido ahora la causante de reproducirlos como principios rectores sin eliminarlos de los objetivos básicos de la Comunidad.

\subsection{Defensor del Pueblo y otras instituciones}

Aunque el Defensor del Pueblo andaluz tiene su sede estatutaria propia en las normas que regulan las "otras instituciones de autogobierno", el Título I del Estatuto contiene también - a semejanza de nuevo del Título I CE - una disposición sobre el mismo, el art. 41 EAA, que le atribuye "velar por la defensa de los derechos enunciados en el presente Título". Su norma reguladora, el art. 128.1 EAA, lo define sin embargo como comisionado por el Parlamento "para la defensa de los derechos y libertades comprendidos en el Título I de la Constitución y en el Título I del presente Estatuto", y dice que a estos efectos podrá "supervisar la actividad de las administraciones públicas de Andalucía”. Es elegido por el Parlamento por mayoría "cualificada" (art. 128.2 EAA).

${ }^{35}$ Así, donde el art. 53 CE dice "El reconocimiento, el respeto y la protección de los principios reconocidos en el Capítulo tercero informarán la legislación positiva, la práctica judicial y la actuación de los poderes públicos. Sólo podrán ser alegados ante la Jurisdicción ordinaria de acuerdo con lo que dispongan las leyes que los desarrollen", el art. 40.1 EAA dice "El reconocimiento y protección de los principios rectores de las políticas públicas informará las normas legales y reglamentarias andaluzas, la práctica judicial y la actuación de los poderes públicos, y podrán ser alegados ante los jueces y tribunales de acuerdo con lo que dispongan las leyes que los desarrollen". 
Junto al Defensor del Pueblo, debe mencionarse como institución estatutaria encargada de "velar por el respeto de los derechos, libertades y valores constitucionales y estatutarios en los medios audiovisuales" el Consejo Audiovisual que establece el art. 131 EAA.

\section{NOTA BIBLIOGRÁFICA}

Aunque la bibliografía sobre el Título I EAA es aún escasa, pueden citarse ya algunos trabajos, tanto sobre la discusión previa a la inclusión de una tabla de derechos en el Estatuto como sobre el articulado de éste. Ver, a este respecto, entre los segundos, Gregorio CÁMARA VILLAR (2007) "Derechos, deberes y principios rectores", en Francisco BALAGUER CALLEJÓN (ed) $E l$ Nuevo Estatuto de Andalucía, Madrid, Tecnos, pp. 23-43; María Luisa BALAGUER CALLEJÓN "Reformas estatutarias y reconocimiento de derechos" $R \boldsymbol{e}$ vista General de Derecho Constitucional 3 (en línea) y Manuel TEROL BECERRA (ed) (2007) La Reforma del Estatuto de Autonomía para Andalucía. Los derechos sociales de los andaluces. Deberes y políticas públicas, Sevilla IAAP, con estudios de Gerardo RUIZ-RICO RUIZ, Miguel REVENGA SÁNCHEZ, Eduardo GAMERO CASADO, Miguel AGUDO ZAMORA, Fernando ÁlVAREZ-OSSORIO MICHEO y María HOLGADO GONZÁLEZ.

La cita en el texto "al día de hoy no existe una construcción dogmática clara respecto del régimen jurídico constitucional de los extranjeros en nuestro país" procede de Camino VIDAL FUEYO (2007) "Nuevas variables a tener en cuenta en el diseño del estatuto jurídico de los inmigrantes", Revista General de Derecho Constitucional 3 (en línea), p. 7. En cuanto a los problemas que crea la cláusula de "mínimo estándar" en diferentes contextos, ver las diferentes aportaciones de Miguel Ángel APARICIO (ed) (2005), Derechos y Libertades en los Estados Compuestos, Barcelona, Atelier, particularmente el resumen de los mismos en la introducción a esa obra, Josep M CASTELLÁ (2005) "El reconocimiento y garantía de los Derechos y Libertades en los Estados compuestos. Una aproximación comparada”, pp. 11-38. Permítaseme remitirme igualmente a dos obras mías sobre el particular: en relación con Estados Unidos, (1997) "La mayor protección de los Derechos Fundamentales: dos ejemplos norteamericanos y algunas enseñanzas para el caso europeo" en Estudios de Derecho Público. Homenaje a Juan José Ruiz-Rico, Madrid, Tecnos, vol. I pp. 365-399 y, sobre Europa, (2001) Integración Europea y Derechos Fundamentales, Madrid, Civitas. En esta última (pp. 79 y ss.) puede encontrarse también un desarrollo de la crítica al tenor literal del art. 10.2 CE que se encuentra en la nota 18 . 
La afirmación en el texto de que, en los derechos prestacionales, es la labor del legislador la que da realmente vida al derecho es tributaria de la teoría "congenial" de los derechos fundamentales de Peter HÄBERLE, en las que es esencial el "diálogo" entre el constituyente y el legislador. Puede verse por ejemplo en Antonio LÓPEZ PINA (1991) La garantía constitucional de los derechos fundamentales. Alemania, España, Francia e Italia, Madrid, Civitas, p. 114 y ss. Una discusión de la distinta concepción de las normas establecedoras de derechos, bien como límites del poder, bien como títulos competenciales, aplicada, precisamente, a la interpretación de los artículos 51.1 y 51.2 CDFUE puede verse en Paloma BIGLINO (2003) "Derechos Fundamentales y competencias de la Unión: el argumento de Hamilton” Revista Española de Derecho Constitucional 69 pp. 387-396. Las limitaciones del carácter social del Tratado Constitucional Europeo de las que se hace eco el texto han sido puestas de manifiesto por Christian JOERGES (2005) "¿Qué tiene de socialdemócrata la Constitución económica europea?”, Revista Española de Derecho Constitucional 73 pp. 9-53, para el que, a la vista de cómo quedó el Tratado, la posibilidad de que con base en el mismo el Tribunal de Justicia elaborara una jurisprudencia activa de respeto de los derechos sociales no deja de ser una "suposición heroica" (p. 50). La afirmación, en fin, de que las prestaciones propias del Estado Social provienen en España fundamentalmente de las CCAA puede contrastarse en Miguel Ángel GARCÍA HERRERA y Gonzalo MAESTRO BUELGA (1999) Marginalidad, Estado social y prestaciones autonómicas, Barcelona, CEDECS.

En el epígrafe dedicado al catálogo de derechos se ha hecho referencia en varias ocasiones a títulos competenciales del nuevo EAA, valiéndonos para ello de lo analizado en las distintas aportaciones en Francisco BALAGUER CALLEJÓN (ed) (2007) Reformas Estatutarias y Distribución de Competencias, Sevilla, Instituto Andaluz de Administración Pública. Me he basado particularmente en mis propias contribuciones sobre "consultas populares" (pp. 875 y ss.) y "medios de comunicación social” (pp. 749 y ss.). Algunas de la afirmaciones vertidas en el texto sobre derechos concretos han tenido en cuenta trabajos como el relativo a las diferentes vías para fundamentar el derecho a una muerte digna en el art. 15 CE de Carmen TOMÁS-VALIENTE LANUZA (2003) "La disponibilidad de la propia vida: aspectos constitucionales", en El derecho a la vida. Actas de las VIII Jornadas de la Asociación de Letrado del Tribunal Constitucional, Madrid, CEPC, pp. 55-73, o el mío propio sobre el derecho de acceso a los documentos en la Unión Europea y su consagración en el art. 42 CDFUE, de nuevo en Integración Europea y Derechos Fundamentales, pp. 225 y ss. En fin, la afirmación de que la vis expansiva del derecho a la buena administración puede compararse con la que en su mo- 
mento tuvo el derecho a la tutela judicial procede de Lorenzo MARTÍN RETORTILLO (2002) "Dos notas sobre la Carta" en Eduardo GARCÍA DE ENTERRÍA y Ricardo ALONSO GARCÍA (eds) La Encrucijada Constitucional de la Unión Europea, Madrid, Civitas, p.195. 